\title{
AUTOMATED CLEAN CHEMISTRY FOR BULK ANALYSIS OF ENVIRONMENTAL SWIPE SAMPLES
}



\section{Approved for public release.} Distribution is unlimited.

Brian W. Ticknor

Shalina C. Bottorff Cole R. Hexel Kayron N. Tevepaugh Debra A. Bostick

October 2016 


\title{
DOCUMENT AVAILABILITY
}

Reports produced after January 1, 1996, are generally available free via US Department of Energy (DOE) SciTech Connect.

\section{Website http://www.osti.gov/scitech/}

Reports produced before January 1, 1996, may be purchased by members of the public from the following source:

\author{
National Technical Information Service \\ 5285 Port Royal Road \\ Springfield, VA 22161 \\ Telephone 703-605-6000 (1-800-553-6847) \\ TDD 703-487-4639 \\ Fax 703-605-6900 \\ E-mail info@ntis.gov \\ Website http://www.ntis.gov/help/ordermethods.aspx
}

Reports are available to DOE employees, DOE contractors, Energy Technology Data Exchange representatives, and International Nuclear Information System representatives from the following source:

Office of Scientific and Technical Information

PO Box 62

Oak Ridge, TN 37831

Telephone 865-576-8401

Fax 865-576-5728

E-mail reports@osti.gov

Website http://www.osti.gov/contact.html

This report was prepared as an account of work sponsored by an agency of the United States Government. Neither the United States Government nor any agency thereof, nor any of their employees, makes any warranty, express or implied, or assumes any legal liability or responsibility for the accuracy, completeness, or usefulness of any information, apparatus, product, or process disclosed, or represents that its use would not infringe privately owned rights. Reference herein to any specific commercial product, process, or service by trade name, trademark, manufacturer, or otherwise, does not necessarily constitute or imply its endorsement, recommendation, or favoring by the United States Government or any agency thereof. The views and opinions of authors expressed herein do not necessarily state or reflect those of the United States Government or any agency thereof. 
Chemical Sciences Division

\title{
AUTOMATED CLEAN CHEMISTRY FOR BULK ANALYSIS OF ENVIRONMENTAL SWIPE SAMPLES
}

\author{
Brian W. Ticknor \\ Shalina C. Bottorff \\ Cole R. Hexel \\ Kayron N. Tevepaugh \\ Debra A. Bostick
}

Date Published: October 2016

\section{Prepared by}

OAK RIDGE NATIONAL LABORATORY

Oak Ridge, TN 37831-6283

managed by

UT-BATTELLE, LLC

for the

US DEPARTMENT OF ENERGY

under contract DE-AC05-00OR22725 



\section{CONTENTS}

\section{LIST OF FIGURES}

\section{LIST OF TABLES}

ACRONYMS

EXEN

EXECUTIVE SUMMARY

1. INTRODUCTION

1.1 DESIGN OF THE PREPFAST-MC2

INSTALLATION OF SYSTEM AT OAK RIDGE NATIO

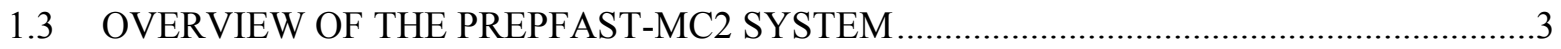

2. EXPERIMENTAL METHODS

2.1 INITIAL COLUMN CALIBRATION.

2.2 COLUMN PACKING AND UNPACKING REPRODUCIBILITY .......................................

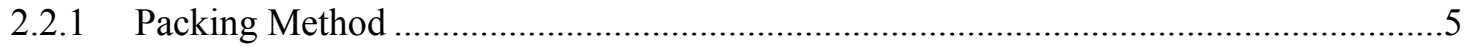

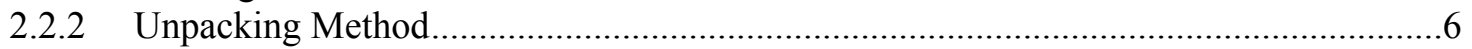



2.3 CHARACTERIZATION OF SYSTEM PROCESS BLANKS ….......................................

2.4 ANALYSIS OF SEPARATED CERTIFIED REFERENCE MATERIALS …......................

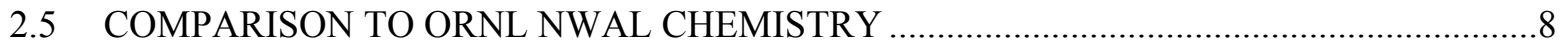

3. RESULTS AND DISCUSSION

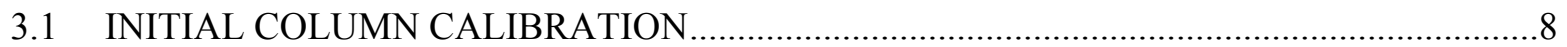

3.2 COLUMN PACKING AND UNPACKING REPRODUCIBILITY ...................................10

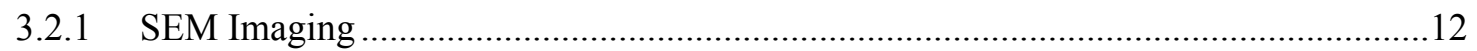

3.3 CHARACTERIZATION OF SYSTEM PROCESS BLANKS ….......................................15

3.4 ANALYSIS OF SEPARATED CERTIFIED REFERENCE MATERIALS .........................18

3.5 COMPARISON TO CURRENT NWAL CAPABILITY ...................................................21

4. TIME AND COST SAVINGS

5. CONCLUSIONS



REFERENCES 



\section{LIST OF FIGURES}

Figure 1. Installation of the prepFAST-MC2 at ORNL.

Figure 2. ESI prepFAST MC-2 valve diagram.

(n)

Figure 3. Uranium UTEVA column calibration runs.

Figure 4. Plutonium TEVA column calibration runs.

.

Figure 5. Combined UTEVA (red) and TEVA (blue) column calibration runs for U/Pu

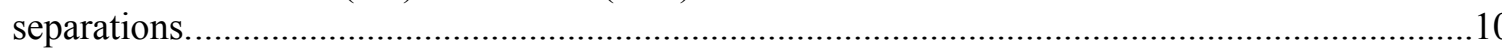

Figure 6. Packing of TEVA (C1) column over 3 days using $500 \mathrm{~mL}$ bottles.

Figure 7. Packing of UTEVA (C2) column over 3 days using $500 \mathrm{~mL}$ bottles.

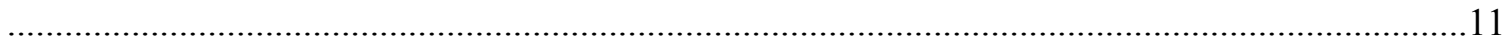

Figure 8. Packing of TEVA (C1) column over 3 days using $125 \mathrm{~mL}$ bottles.

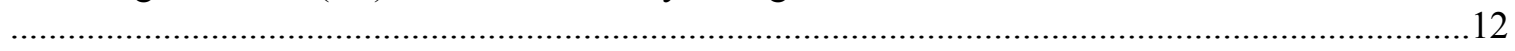

Figure 9. Packing of UTEVA (C2) column over 3 days using $125 \mathrm{~mL}$ bottles.

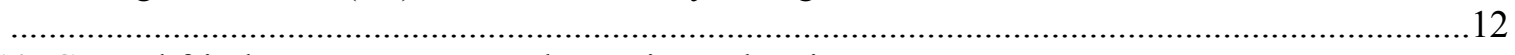

Figure 10. Control frit that was not exposed to resin or chemistry.

Figure 11. Frit from C1 column after 30 pack/unpack trials; no chemistry was performed.

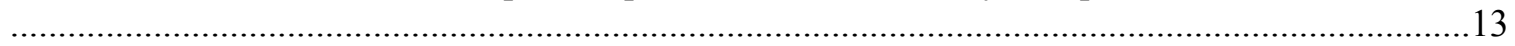

Figure 12. Frit from C2 column after 30 pack/unpack trials; no chemistry was performed.

Figure 13. Frit from $\mathrm{C} 1$ column after 14 separations $(\sim 75 \%$ blockage $)$.

Figure 14. Frit from $\mathrm{C} 2$ column after 14 separations $(<5 \%$ blockage $)$.

Figure 15. Average and total $U$ in spiked blank samples after spike stripping with $2 \sigma$ error bars compared to the average value from the ORNL NWAL manual chemistry process blanks for 2015-2016 (black)...................................................................................................

Figure 16. Average and total Pu in spiked blank samples after spike stripping with $2 \sigma$ error bars
compared to the average value from the ORNL NWAL manual chemistry process blanks

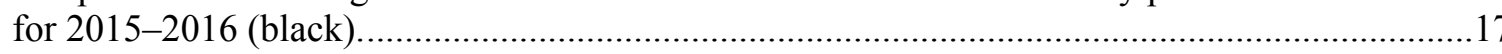

Figure 17. Counts of $U$ in blanks spiked with IRMM-57 $\left({ }^{233} \mathrm{U}\right)$.

Figure 18. Counts of $\mathrm{Pu}$ in blanks spiked with RAL-22 $\left({ }^{244} \mathrm{Pu}\right)$.

Figure 19. Average and total amount of $\mathrm{U}$ (left) and $\mathrm{Pu}$ (right) in unspiked blank samples (blue)

run intermittently with mixed CRM samples compared to the average ORNL NWAL manual chemistry process blanks for 2015-2016 (black).

Figure 20. Major $\left({ }^{235 / 238} \mathrm{U}\right)$ and minor $\left({ }^{236 / 238} \mathrm{U}\right)$ isotope ratios of $U$ in samples compared to the

average value (black line) and $2 \sigma$ (green area) and $3 \sigma$ (magenta area) uncertainties of the
replicate analyses of the corresponding control standards control samples of IRMM-183

average value (black line) and $2 \sigma$ (green area) and $3 \sigma$ (magenta area) uncertainties of the
replicate analyses of the corresponding control standards control samples of IRMM-183

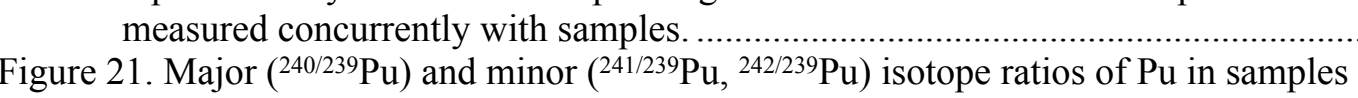
compared to the certified value (black line) and $2 \sigma$ (green area) and $3 \sigma$ (magenta area) uncertainties from the CRM certificate isotope ratios for CRM NBL-137. 
Figure 22. Time comparison chart of ORNL NWAL manual chemistry and ESI prepFAST-MC2 automated system with total time and hands-on time shown. 



\section{LIST OF TABLES}

Table 1. Final resin packing method

Table 2. Final resin unpacking methods

Table 3. Method description for the separation of U/Pu with the ESI system

Table 4. Chemistry differences in ESI prepFAST-MC2 and ORNL NWAL manual chemistry

Table 5. Major and minor isotope ratios for $\mathrm{U}$ and $\mathrm{Pu}$ compared to $\mathrm{CRM}$ values

Table 6. Time comparison of ORNL NWAL manual chemistry and ESI prepFAST-MC2 automated system 



\section{ACRONYMS}

ASTM

COTS

CRM

ESI

HRICPMS

IAEA

IDMS

IRMM

ISO

JCR-EC

$\mathrm{M} / \mathrm{C}$

MCICPMS

MCTIMS

NIST

NWAL

ORNL

SEM

SOP

SRM

ULPA
American Society for Testing and Materials

Commercial Off the Shelf

Certified Reference Material

Elemental Scientific Incorporated

High-Resolution Inductively Coupled Plasma Mass Spectrometer International Atomic Energy Agency

Isotope Dilution Mass Spectroscopy

Institute for Reference Materials and Measurements

International Standards Organization

Joint Research Center of the European Commission

Measured/Certified

Multi-Collector Inductively Coupled Plasma Mass Spectrometer

Multi-Collector Thermal Ionization Mass Spectrometer

National Institute of Standards and Technology

Network of Analytical Laboratories

Oak Ridge Nation Laboratory

Scanning Electron Microscope

Standard Operating Procedure

Standard Reference Material

Ultra-Low Penetration Air 



\section{ACKNOWLEDGMENTS}

The authors would like to thank Paul Field and Hwan Kim of Elemental Scientific Inc. (ESI) for providing the prototype prepFAST-MC2 as well as troubleshooting guidance throughout this work. Authors would also like to thank Dr. Christopher P. Milojevich at ORNL for collecting the SEM images.

This work is supported by the Safeguards Technology Development Program, Office of Nonproliferation and Arms Control, at the Department of Energy's National Nuclear Security Administration under contract DE-AC05-00OR22725 with UT-Battelle, LLC. 



\section{EXECUTIVE SUMMARY}

To shorten the lengthy and costly manual chemical purification procedures, sample preparation methods for mass spectrometry are being automated using commercial-off-the-shelf (COTS) equipment. This addresses a serious need in the nuclear safeguards community to debottleneck the separation of $\mathrm{U}$ and $\mathrm{Pu}$ in environmental samples - currently performed by overburdened chemists - with a method that allows unattended, overnight operation. In collaboration with Elemental Scientific Inc., the prepFAST-MC2 was designed based on current COTS equipment that was modified for $\mathrm{U} / \mathrm{Pu}$ separations utilizing Eichrom ${ }^{\mathrm{TM}}$ TEVA and UTEVA resins.

Initial verification of individual columns yielded small elution volumes with consistent elution profiles and good recovery. Combined column calibration demonstrated ample separation without crosscontamination of the eluent. Automated packing and unpacking of the built-in columns initially showed $>15 \%$ deviation in resin loading by weight, which can lead to inconsistent separations. Optimization of the packing and unpacking methods led to a reduction in the variability of the packed resin to less than $5 \%$ daily.

The reproducibility of the automated system was tested with samples containing $30 \mathrm{ng} \mathrm{U}$ and $15 \mathrm{pg} \mathrm{Pu}$, which were separated in a series with alternating reagent blanks. These experiments showed very good washout of both the resin and the sample from the columns as evidenced by low blank values. Analysis of the major and minor isotope ratios for $\mathrm{U}$ and $\mathrm{Pu}$ provided values well within data quality limits for the International Atomic Energy Agency. Additionally, system process blanks spiked with ${ }^{233} \mathrm{U}$ and ${ }^{244} \mathrm{Pu}$ tracers were separated using the automated system after it was moved outside of a clean room and yielded levels equivalent to clean room blanks, confirming that the system can produce high quality results without the need for expensive clean room infrastructure.

Comparison of the amount of personnel time necessary for successful manual vs. automated chemical separations showed a significant decrease in hands-on time from 9.8 hours to 35 minutes for seven samples, respectively. This documented time savings and reduced labor translates to a significant cost savings per sample. Overall, the system will enable faster sample reporting times at reduced costs by limiting personnel hours dedicated to the chemical separation. 



\section{INTRODUCTION}

Streamlining sample preparation methods for mass spectrometry by the introduction of fully automated, commercial-off-the-shelf (COTS) equipment would address a serious need in the safeguards community by speeding up lengthy and costly manual chemical purification procedures. Presently, the International Atomic Energy Agency (IAEA), and its associated Network of Analytical Laboratories (NWAL), uses mass spectrometry as a key analysis technique in the bulk environmental sampling program. The current method for analysis of swipe samples utilizes high-precision multi-collector mass spectrometry to produce highly accurate and precise isotopic data. To reduce interferences and minimize matrix effects, extensive purification procedures are used to isolate actinide elements from their natural matrix. Purification protocols require manually loading gravity-driven separation columns, a process that is both expensive and time-consuming. Automating the chemical separation, while still producing a highly purified sample, will offer significant savings in both time and money to the IAEA without sacrificing data quality. Finally, the use of COTS equipment will allow an automated method to be quickly and economically transferred to and implemented by any NWAL laboratory, helping the IAEA globally execute standard operating procedures (SOP) for isotopic purification while addressing the ongoing challenges of backlogged samples.

NWAL laboratories perform destructive analysis of exposed cotton swipe samples acquired during on-site inspections of safeguarded facilities to aid IAEA in making Bias Defect determinations, ${ }^{1}$ where small amounts of nuclear material may be missing. Actinide elements, particularly $\mathrm{U}$ and $\mathrm{Pu}$, are measured for isotopic composition and concentration. Typical characteristics of collected field samples are $1 \mathrm{ng}$ to $10 \mathrm{mg} \mathrm{U} / \mathrm{swipe}$ and $<1 \mathrm{ng} \mathrm{Pu} / \mathrm{swipe}$. The Measurement Quality Goals set forth by the IAEA for the bulk analysis program are $\mathrm{a} \leq 2 \%$ relative expanded uncertainty for ${ }^{235} \mathrm{U} /{ }^{238} \mathrm{U}$ and $\leq 20 \%$ for ${ }^{234} \mathrm{U} /{ }^{238} \mathrm{U}$ and ${ }^{236} \mathrm{U} /{ }^{238} \mathrm{U}$ at $>10 \mathrm{ng} \mathrm{U}$ and $\leq 20 \%$ for all $\mathrm{Pu}$ isotope ratios at $>1 \mathrm{pg}$ at a $95 \%$ confidence level. ${ }^{2}$ This is currently achieved by either multi-collector inductively coupled plasma mass spectrometry (MCICPMS) or multi-collector thermal ionization mass spectrometry (MCTIMS). Both of these techniques/instruments require highly purified samples, free from interferences such as organics and heavy metals, to ensure the quality of the high-accuracy measurement. Manual purification chemistry typically adds multiple days to the analysis time.

The goal of this project is to automate the chemical separations with a system that allows unattended, overnight operation. This will enable quicker sample reporting times and reduce costs by limiting personnel hours dedicated to bench chemistry. Additional benefits may include lower and more consistent blank levels for $\mathrm{U}$ and $\mathrm{Pu}$ and the ability to achieve cleanroom level blanks without the infrastructure needs of a certified International Standards Organization (ISO) cleanroom. This project aims to directly address high-priority Milestones 10.2 and 10.3 in the IAEA Long-Term R\&D Plan (STR-375) ${ }^{3}$ by developing new technologies and techniques that will improve the NWAL's ability to provide analytical services to IAEA. By supporting STR-375, this work also addresses the short-term needs described in the Development and Implementation Support Programme for Nuclear Verification 2016-2017 document. ${ }^{4}$ Specifically, transfer of this automated COTS technology to NWAL member laboratories supports SGAS-003, Analysis Support and NWAL Coordination, and especially the top priority to "Ensure efficient and effective operation of the NWAL." 4

\subsection{DESIGN OF THE PREPFAST-MC2}

In December of 2015, Oak Ridge National Laboratory (ORNL) personnel traveled to Elemental Scientific Inc. (ESI) headquarters in Omaha, Nebraska, to meet with collaborators Paul Field and Hwan Kim. At this initial meeting the specific ORNL NWAL chemical purification procedures were shared with ESI, and designs were made to customize the existing ESI product line, the prepFAST-MC, to the specific application of bulk environmental $\mathrm{U}$ and $\mathrm{Pu}$ separations. 
The ESI prepFAST-MC system is constructed with a proprietary assembly of valves and pumps that control sample flow throughout the process. This system has a well-documented performance record for similar types of separations using Eichrom resins. An ESI prepFAST-MC installed in a university laboratory demonstrated extremely high chemical recovery (98\%) for 26 consecutive uranium samples on the same column. Greater than $99.999 \%$ of major matrix contaminants, such as $\mathrm{Na}, \mathrm{Mg}, \mathrm{Al}, \mathrm{Ca}$, and $\mathrm{Fe}$, were successfully removed from the final fraction. A uranium reference material processed through the system concurrently with samples of natural uranium and then analyzed by MCICPMS showed external precision for the measurement of ${ }^{238} \mathrm{U} /{ }^{235} \mathrm{U}$ of $0.03 \% .^{5}$

However, the simultaneous separation of both $\mathrm{U}$ and $\mathrm{Pu}$ from the same sample had not been demonstrated. This required two different Eichrom resins, TEVA for Pu recovery and UTEVA for U recovery, in two sequential columns. Moreover, testing at ORNL on the reuse of the TEVA resin showed that recovery of $\mathrm{Pu}$ dropped significantly with multiple uses. Issues associated with the reuse of the TEVA resin, along with quality assurance concerns about the reuse of the UTEVA resin for multiple samples, led to the decision to automate the packing and unpacking of the columns with fresh resin for each and every sample.

\subsection{INSTALLATION OF SYSTEM AT OAK RIDGE NATIONAL LABORATORY}

The newly designed ESI prepFAST-MC2 was delivered in March 2016, as shown in Figure 1. ESI provided onsite support for the installation, which was originally done in a class 100 clean room in the Ultra-Trace Forensic Science Center located at ORNL. Eventually it was moved to a different, non-clean room laboratory in the same building, which is where most of the testing described below took place. The system was designed to closely mirror the ORNL NWAL chemistry procedure but was modified from the fully COTS prepFAST-MC to automatically pack and unpack both the TEVA and UTEVA columns with fresh resin for each sample.

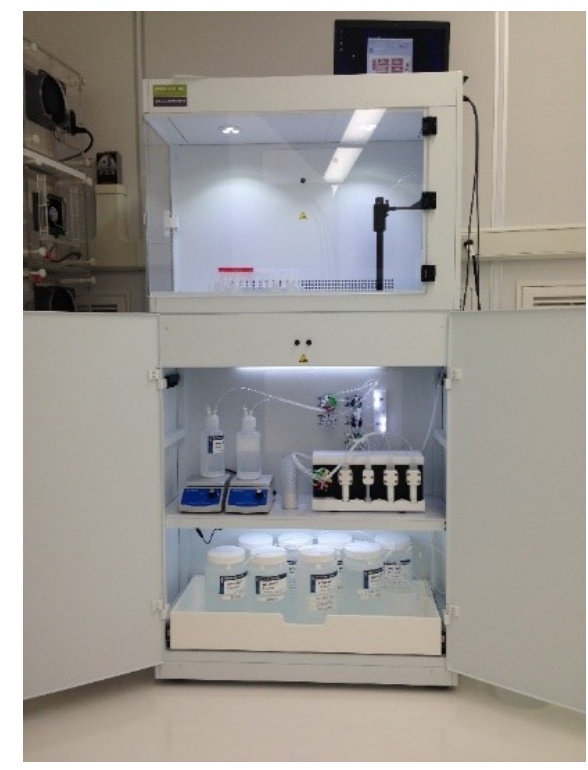

Figure 1. Installation of the prepFAST-MC2 at ORNL.

The system is appropriate for installation in a clean room environment (but a clean room is not required). Much of the frame is plastic, and any exposed metal is powder coated to prevent metal particles from being released into the laboratory or system. All the reagents are held in plastic bottles on a retractable shelf in the bottom of the cabinet. The shelf and cabinet together serve as secondary containment for the acids used. The resins are contained in bottles on the middle shelf of the cabinet and are placed on stir 
plates that turn while the system is operating, ensuring homogenization of the resin/acid mixture. The laboratory infrastructure requirements for the system are minimal and are listed in the Pre-Installation Guide provided by ESI. Briefly, the requirements are as follows:

- Space: $826 \mathrm{~mm} \mathrm{~L} \times 430 \mathrm{~mm} \mathrm{~W} \times 1625 \mathrm{~mm} \mathrm{H}$ (from the floor)

- Power outlet within $3 \mathrm{~m}$ of instrument $(120 \mathrm{~V} / 60 \mathrm{~Hz})$

- Exhaust with $69 \mathrm{~mm}$ ID to fit the back panel and a flow rate of 40 cubic feet per minute

- 5 bar of gas pressure $\left(\mathrm{Ar}\right.$ or $\left.\mathrm{N}_{2}\right)$

Ultrapure reagents, including acids and American Society for Testing and Materials (ASTM) Type I $(18.2 \mathrm{M} \Omega)$ water, are strongly recommended. Additionally, the specifications for the resins used by the system are below, with the recommendation to have at least one $100 \mathrm{~g}$ bottle of each resin on hand for installation.

- UTEVA Resin: Eichrom; 50-100 $\mu$ m; Part No. UT-B100-S

- TEVA Resin: Eichrom; 50-100 $\mu \mathrm{m}$; Part No. TE-B100-S

\subsection{OVERVIEW OF THE PREPFAST-MC2 SYSTEM}

Figure 2 shows a schematic diagram of the valves that make up the heart of the separation system. Samples are introduced to the prepFAST-MC via the Probe, which also serves to dispense separated sample aliquots into specified vials after column purification. The system is driven by four syringe pumps that are integrated with the valves shown in Figure 2. The V9 valve on the left of Figure 2 is responsible for loading and unloading the resins into the columns, while the V9 valve on the right dispenses the appropriate reagents to the columns. Port M8 is connected to the compressed gas line that is used to unpack the spent resin from the column after a sample separation. Port V1 P7 actually loads resins and reagents (via the two V9 valves) and the sample (via the Probe) to the TEVA column, while V2 P7 loads the UTEVA column. The M10 valve loads the sample and reagents on a loop before they are put onto the packed column. The whole sample line, including the loop, is closed, so that the sample only comes in contact with Teflon tubing, which helps to minimize environmental contamination even if the system is not located in a clean room. Additionally, when a reagent or sample is loaded onto the loop, it is pushed by an air bubble rather than the next reagent. This liquid/air interface prevents mixing of different reagents with each other and/or the sample as multiple solution matrices are pumped through the same lines.

The entire assembly is controlled by a laptop computer (provided by ESI) that runs the commercial ESI SC software. The chemistry method employed on the prep-FAST-MC2 is "programmed" through the software. Most variables can be easily adjusted by modifying the separation program being used. This includes parameters such as reagent volumes and flow rates. Additionally, the software interface specifies the location of the samples and defines where separated aliquots are to be dispensed. This can be combined with an optional bar code reader to track individual samples via a bar code marking molded into the vial. The reader adds a layer of transcription protection from a sample tracking and chain-ofcustody point of view. Additionally, it allows the system to check for the presence of the appropriate vial at each location in the sample tray before dispensing an aliquot, limiting the potential for loss of sample due to human error in the event of misloading vials. 




Figure 2. ESI prepFAST MC-2 valve diagram.

\section{EXPERIMENTAL METHODS}

Only ultrapure reagents were used, with low trace metal content the major consideration in reagent selection. Optima ${ }^{\mathrm{TM}} \mathrm{HNO}_{3}, \mathrm{HCl}$, and $\mathrm{HF}$ was purchased through Fisher Scientific and used without further purification. $\mathrm{NaNO}_{2}$ (ACS, 95\% min) and $\mathrm{FeSO}_{4}$ Puratronic ${ }^{\circledR}$ 99.999\% (metals basis) were purchased through Alfa Aesar and used without further purification. ASTM Type I (18.2 M 2 ) water was generated with a Thermo Scientific ${ }^{\mathrm{TM}}$ Barnstead $^{\mathrm{TM}}$ GenPure $^{\mathrm{TM}}$ Pro Water Purification System. TEVA-resin and UTEVA-resin (20-50 $\mu \mathrm{m}$ particle size) were purchased from Eichrom Industries, Inc. Certified Reference Materials (CRMs) for $\mathrm{U}$ and Pu were purchased from the New Brunswick Laboratory (NBL-137, Pu) or the Institute for Reference Materials and Measurements [IRMM-183 (U), IRMM-57 (U), IRMM-82 (Pu)], now the Joint Research Center of the European Commission (JRC-EC). An internal ORNL solution of high-purity ${ }^{244} \mathrm{Pu}$ (RAL 22) was used as an isotope dilution spike to determine sample Pu recovery. Its concentration was determined relative to National Institute of Standards and Technology (NIST) Standard Reference Material (SRM) 4330C. 
All mass spectrometric data presented in this report was collected on either a high-resolution inductively coupled plasma mass spectrometer (HRICPMS) or an MCICPMS. A ThermoScientific Element II (Bremen, Germany) was utilized for all HRICPMS measurements. The Element II is a single collector magnetic sector mass spectrometer typically used for elemental analysis. It works by quickly scanning the magnetic field to direct ions sequentially onto the detector. In the present experiments, the Element II was used during the column calibration step to quickly scan column elution fractions for both $\mathrm{U}$ and $\mathrm{Pu}$ to verify separation and approximate the recovery.

A ThermoScientific Neptune Plus (Bremen, Germany) was used for all MCICPMS measurements. The Neptune Plus is used for ORNL NWAL analysis of both $\mathrm{U}$ and $\mathrm{Pu}$ isotope ratio measurements and was used here to characterize the mixed CRM samples that were separated on the ESI prepFAST-MC2. The MCICPMS obtains highly accuracy and precise isotope ratio measurements by monitoring all isotopes of $\mathrm{U}$ or Pu simultaneously on different detectors. U samples in the nanogram range are typically measured using faraday cup detectors, while the much smaller Pu samples (picograms) are measured using multiple ion counting detectors. As a result of the mass differences between $\mathrm{U}$ and $\mathrm{Pu}$, as well as isobaric interferences such as ${ }^{238} \mathrm{U}$ and ${ }^{238} \mathrm{Pu}, \mathrm{U}$ and $\mathrm{Pu}$ are measured in separate, purified aliquots during different analytical sessions.

Scanning electron microscope (SEM) images were taken on a FEI Phenom operating at $5 \mathrm{kV}$. The electron source was a tungsten emitter. The samples were affixed to a SEM stub with a carbon conductive tab and then imaged at 500× magnification. Multiple image locations were selected at random on each sample.

\subsection{INITIAL COLUMN CALIBRATION}

Solutions of IRMM-183 $\left(0.3 \%{ }^{235} \mathrm{U} /{ }^{238} \mathrm{U}\right)$ and NBL-137 $\left(0.241{ }^{240} \mathrm{Pu} /{ }^{239} \mathrm{Pu}\right)$ were used to make individual samples that contained $5 \mathrm{ng}$ of depleted $\mathrm{U}$ and $2 \mathrm{pg}$ of $\mathrm{Pu}$. These were then diluted with $3 \mathrm{M} \mathrm{HNO}_{3}$. The samples were individually processed through the ESI prepFAST-MC2 system, and each $1 \mathrm{~mL}$ eluent fraction was collected for initial calibration of the columns. A mixed U/Pu sample was made with the same concentrations of IRMM-183 and NBL-137 and separated on the system using the same method.

\subsection{COLUMN PACKING AND UNPACKING REPRODUCIBILITY}

Packing tests on the prepFAST-MC2 were conducted using two $1 \mathrm{~mL}$ Teflon columns $(\mathrm{C} 1$ and $\mathrm{C} 2)$ that were packed with TEVA $\left(4.05 \pm 0.11 \mathrm{~g}\right.$ suspended in $\left.55.52 \pm 0.20 \mathrm{~g} 3 \mathrm{M} \mathrm{HNO}_{3}\right)$ and UTEVA $\left(4.04 \pm 0.08 \mathrm{~g}\right.$ suspended in $\left.55.45 \pm 0.19 \mathrm{~g} 3 \mathrm{M} \mathrm{HNO}_{3}\right)$, respectively, over the duration of the trials. Unpacked resin was collected in disposable columns, vacuum filtered, air dried for $10 \mathrm{~min}$, and then weighed. Experiments were conducted over the course of several days, with new resin batches made daily.

\subsubsection{Packing Method}

The resin packing method is outlined in 
Table 1. To summarize, the columns are rinsed with water and the syringes are filled before the resin is primed, without entering the columns, through the V9 port to the V1/V2 ports, as shown in Figure 2. Extra resin in the line after the V9 port and any liquid in the columns is then purged to waste. The loop is filled with air, and the columns are packed simultaneously with resin. Once the columns are full, the resin lines between the V9 and V1/V2 ports are purged of any residual resin and the columns are then purged with air sequentially $(\mathrm{C} 1$ then $\mathrm{C} 2)$. 
Table 1. Resin packing method

\begin{tabular}{cl}
\hline Step No. & \multicolumn{1}{c}{ Description: reagent (flow rate) } \\
\hline $\mathbf{1}$ & Rinse columns: $12 \mathrm{~mL}$ water $(10 \mathrm{~mL} / \mathrm{min})$ and reset syringes \\
$\mathbf{2}$ & Prime resin lines: $\mathrm{C} 1-1.55 \mathrm{~mL}, \mathrm{C} 2-1.35 \mathrm{~mL}(2 \mathrm{~mL} / \mathrm{min})$ \\
$\mathbf{3}$ & Purge residual resin: $7 \mathrm{~mL}$ water $(20 \mathrm{~mL} / \mathrm{min})$ and fill loop with air \\
$\mathbf{4}$ & Pack columns: $\mathrm{C} 1$ and $\mathrm{C} 24.25 \mathrm{~mL}$ resin slurry $(0.85 \mathrm{~mL} / \mathrm{min})$ \\
$\mathbf{5}$ & Purge excess resin: $5 \mathrm{~mL}$ water $(20 \mathrm{~mL} / \mathrm{min})$ \\
$\mathbf{6 a}$ & Air purge $\mathrm{C} 1$ column $(10 \mathrm{sec})$ \\
$\mathbf{6 b}$ & Air purge $\mathrm{C} 2$ column $(10 \mathrm{sec})$ \\
\hline
\end{tabular}

\subsubsection{Unpacking Method}

The unpacking methods for the two columns are outlined in Table 2. They are identical except for the first step and occur sequentially, with the $\mathrm{C} 2$ column unpacking first followed by the $\mathrm{C} 1$ column. Initially $\mathrm{C} 2$ is blown out with compressed $\mathrm{N}_{2}$ gas and then rinsed with $5 \% \mathrm{HNO}_{3}$ four times, whereas $\mathrm{C} 1$ is rinsed with $5 \% \mathrm{HNO}_{3}$ initially and then blown out with $\mathrm{N}_{2}$. The first rinse is dispensed slowly while $\mathrm{N}_{2}$ is flowing to encourage vigorous movement of the $\mathrm{HNO}_{3}$ within the column to expel all resin material. The next three rinses fill the column and then expel all liquid with $\mathrm{N}_{2}$ before flushing the column again. Finally, the resin in the main resin line is purged back to the resin bottle from the $\mathrm{V} 9$ port with $5 \% \mathrm{HNO}_{3}$.

Table 2. Resin unpacking method

\begin{tabular}{cl}
\hline Step No. & \multicolumn{1}{c}{ Description: reagent (flow rate) } \\
\hline $\mathbf{1}$ & Purge: $\mathrm{C} 2$ resin with $\mathrm{N}_{2} ; \mathrm{C} 1$ resin with $2 \mathrm{~mL} 5 \% \mathrm{HNO}_{3}(2 \mathrm{~mL} / \mathrm{min})$ \\
$\mathbf{2 a}$ & Vigorous wash: $12 \mathrm{~mL} 5 \% \mathrm{HNO}_{3}(5 \mathrm{~mL} / \mathrm{min})$ with $\mathrm{N}_{2}$ flow \\
2b & Purge residual resin/solution with $\mathrm{N}_{2}$ \\
$\mathbf{3 a}$ & Flush column with $12 \mathrm{~mL}$ of $5 \% \mathrm{HNO}_{3}(20 \mathrm{~mL} / \mathrm{min})$ \\
$\mathbf{3 b}$ & Purge solution with $\mathrm{N}_{2}$ \\
$\mathbf{4 - 5}$ & Repeat step 3 twice more $(3$ total $)$ \\
$\mathbf{6}$ & Resin line purge: $3.7 \mathrm{~mL} 5 \% \mathrm{HNO}_{3}(10 \mathrm{~mL} / \mathrm{min})$ \\
\hline
\end{tabular}

\subsubsection{Separations Chemistry Method}

The separations chemistry method is outlined in Table 3. Briefly, after the columns are packed as described in 
Table 1, the sample is loaded and flows through the columns ( $\mathrm{C} 1$ to $\mathrm{C} 2$ ), which are then sequentially washed with $3 \mathrm{M} \mathrm{HNO}_{3}$. The columns are treated individually with an additional $3 \mathrm{M} \mathrm{HNO}_{3}$ wash. $\mathrm{C} 1$ is rinsed with $\mathrm{HCl}$ to convert the TEVA resin to the chloride form. Next, the $\mathrm{U}$ fraction is eluted, followed by the $\mathrm{Pu}$ fraction. Finally, both columns are unpacked as described in Table 2. 
Table 3. Method description for the separation of U/Pu with the ESI system

\begin{tabular}{|c|c|}
\hline Step No. & Description: reagent (flow rate) \\
\hline 1 & Pack TEVA $(\mathrm{C} 1)$ and UTEVA $(\mathrm{C} 2)$ resin columns \\
\hline 2 & Load sample: $3 \mathrm{~mL}$ of sample ( $1 \mathrm{~mL} / \mathrm{min})$ \\
\hline 3 & Wash columns (C1 and $\mathrm{C} 2): 3 \mathrm{~mL}$ of $3 \mathrm{M} \mathrm{HNO}_{3}(2 \mathrm{~mL} / \mathrm{min})$ \\
\hline $4 \mathbf{a}$ & Wash column $\mathrm{C} 1: 3 \mathrm{~mL}$ of $3 \mathrm{M} \mathrm{HNO}_{3}(2 \mathrm{~mL} / \mathrm{min})$ \\
\hline $4 b$ & Wash column $\mathrm{C} 2: 3 \mathrm{~mL}$ of $3 \mathrm{M} \mathrm{HNO}_{3}(2 \mathrm{~mL} / \mathrm{min})$ \\
\hline 5 & Convert to chloride (C1): $2 \mathrm{~mL}$ of $9 \mathrm{M} \mathrm{HCl}(2 \mathrm{~mL} / \mathrm{min})$ \\
\hline 6 & Elute $\mathrm{U}(\mathrm{C} 2): 2 \mathrm{~mL}$ of $0.02 \mathrm{M} \mathrm{HNO}_{3}-0.005 \mathrm{M} \mathrm{HF}(1 \mathrm{~mL} / \mathrm{min})$ twice \\
\hline 7 & Elute $\mathrm{Pu}(\mathrm{C} 1): 4 \mathrm{~mL}$ of $0.1 \mathrm{M} \mathrm{HCl}-0.06 \mathrm{M} \mathrm{HF}(1 \mathrm{~mL} / \mathrm{min})$ twice \\
\hline 8 & Unpack UTEVA (C2) resin sorbent \\
\hline 9 & Unpack TEVA $(\mathrm{C} 1)$ resin sorbent \\
\hline
\end{tabular}

\subsection{CHARACTERIZATION OF SYSTEM PROCESS BLANKS}

General Procedures for Sample Preparation: In a class 100 clean room, a mixed solution of ${ }^{233} \mathrm{U} /{ }^{244} \mathrm{Pu}$ was prepared from IRMM-57 and RAL-22 standards to yield a final solution containing $0.274 \mathrm{ng} / \mathrm{g}{ }^{233} \mathrm{U}$ and $1.128 \mathrm{pg} / \mathrm{g}{ }^{244} \mathrm{Pu}$ in $3 \mathrm{M} \mathrm{HNO}_{3}$. The mixed U/Pu solution $(27 \mathrm{~mL})$ was added to a $50 \mathrm{~mL}$ centrifuge tube. The valence state of the $\mathrm{Pu}$ was adjusted to $\mathrm{Pu}(\mathrm{IV})$ by adding $\mathrm{FeSO}_{4}(1.8 \mathrm{~mL}, 1.7 \mathrm{M})$. The tube was capped and swirled to promote mixing. After approximately $5 \mathrm{~min}$, a color change from clear to green and back to clear occurred; $\mathrm{NaNO}_{2}(3.6 \mathrm{~mL}, 3 \mathrm{M})$ was then added, and the sample was mixed and allowed to degas for 15 min prior to column separation.

General Resin Preparation: TEVA resin contained in a disposable column was rinsed with $3 \mathrm{M} \mathrm{HNO}_{3}$ $(15 \mathrm{~mL})$ via vacuum filtration and transferred to resin bottle one using $3 \mathrm{M} \mathrm{HNO}_{3}$ to yield a final resin$3 \mathrm{M} \mathrm{HNO}_{3}$ mass ratio of $0.0730 \pm 0.0018 \mathrm{~g}$. UTEVA resin contained in a disposable column was rinsed with $0.01 \mathrm{M} \mathrm{HNO}_{3}(15 \mathrm{~mL})$ followed by $3 \mathrm{M} \mathrm{HNO}_{3}(5 \mathrm{~mL})$ via vacuum filtration and transferred to resin bottle two using $3 \mathrm{M} \mathrm{HNO}_{3}$ to yield a final resin-3 $\mathrm{M} \mathrm{HNO}_{3}$ mass ratio of $0.0728 \pm 0.0019 \mathrm{~g}$.

\subsection{ANALYSIS OF SEPARATED CERTIFIED REFERENCE MATERIALS}

General Procedures for Blank and Sample Preparation: A mixed solution of U/Pu was prepared from IRMM-183 (U) and NBL-137 (Pu) standards. Approximate concentrations were $15 \mathrm{ng} / \mathrm{mL} \mathrm{U}$ and $5 \mathrm{pg} / \mathrm{mL} \mathrm{Pu}$ in $3 \mathrm{M} \mathrm{HNO}_{3}$. In a class 100 clean room, $9 \mathrm{~mL}$ of $3 \mathrm{M} \mathrm{HNO}_{3}$ was added to a $50 \mathrm{~mL}$ centrifuge tube to prepare a reagent blank and $9 \mathrm{~mL}$ of the U/Pu solution was added to a different tube for the sample. $\mathrm{FeSO}_{4}(1.7 \mathrm{M}, 800 \mu \mathrm{L}$ and $600 \mu \mathrm{L})$ was added to the blank and sample, respectively. The tubes were capped and swirled to promote mixing. After approximately $5 \mathrm{~min}$, a color change from clear to green and back to clear occurred; $\mathrm{NaNO}_{2}(3 \mathrm{M}, 1.6 \mathrm{~mL}$ and $1.2 \mathrm{~mL})$ was then added to the blank and sample, respectively. Both reactions were mixed and allowed to degas for $15 \mathrm{~min}$ prior to separation.

General Resin Preparation: TEVA resin in a disposable column was rinsed with $15 \mathrm{~mL}$ of $3 \mathrm{M} \mathrm{HNO}_{3}$ via vacuum filtration and transferred to resin bottle one using $3 \mathrm{M} \mathrm{HNO}_{3}$ to yield a final resin-3 $\mathrm{M} \mathrm{HNO}_{3}$ ratio of $0.0741 \pm 0.0029 \mathrm{~g}$. UTEVA resin in a disposable column was rinsed with $0.01 \mathrm{M} \mathrm{HNO}_{3}(15 \mathrm{~mL})$ followed by $3 \mathrm{M} \mathrm{HNO}_{3}(5 \mathrm{~mL})$ via vacuum filtration and transferred to resin bottle two using $3 \mathrm{M} \mathrm{HNO}_{3}$ to yield a final resin-3 $\mathrm{M} \mathrm{HNO}_{3}$ ratio of $0.0730 \pm 0.0013$. 


\subsection{COMPARISON TO ORNL NWAL CHEMISTRY}

Experimentally, the chemistry performed by the prepFAST-MC2 is intentionally very similar to the ORNL NWAL manual chemistry method. Some differences are briefly outlined in Table 4.

Table 4. Chemistry differences in ESI prepFAST-MC2 and ORNL NWAL manual chemistry

\begin{tabular}{c|cc}
\hline Parameter & ESI prepFAST-MC2 & ORNL NWAL Manual Chemistry \\
\hline Column Size & $1 \mathrm{~mL}$ & $2 \mathrm{~mL}$ \\
U Elution & $4 \mathrm{~mL}$ & $5 \mathrm{~mL}$ \\
Pu Elution & $8 \mathrm{~mL}$ & $12 \mathrm{~mL}$ \\
Pu Elution Reagent & $0.1 \mathrm{M} \mathrm{HCl}-0.06 \mathrm{M} \mathrm{HF}$ & $0.1 \mathrm{M} \mathrm{HCl}-0.06 \mathrm{M} \mathrm{HF}-0.02 \mathrm{M} \mathrm{NH}_{4} \mathrm{I}$ \\
\hline
\end{tabular}

\section{RESULTS AND DISCUSSION}

\subsection{INITIAL COLUMN CALIBRATION}

Because ESI could not handle Pu at its facility, the column elution profiles were determined at ORNL after installation of the prepFAST-MC2. The calibration of the columns was initially done independently, with a sample containing just U (5 ng IRMM-183) loaded on the UTEVA column and a sample of just Pu (2 pg NBL-137) loaded on the TEVA column. Then, a mixed U/Pu sample was run through the system. The profiles were determined by collecting the entire volume of acid used for the elution in $1 \mathrm{~mL}$ fractions and then analyzing each aliquot for $\mathrm{U}$ or $\mathrm{Pu}$ (or both) by HRICPMS. The process was repeated twice to ensure reproducibility. These full calibration experiments ensure that in the final automated method, the $\mathrm{U}$ and $\mathrm{Pu}$ aliquots taken for analysis contain the entire sample that will elute off the column. They also serve to verify that the $\mathrm{U}$ and $\mathrm{Pu}$ are fully separated from each other in the recovered samples. This study was conducted while the instrument was located in the class 100 clean room.

As Figure 3 shows, calibration of U elution on the UTEVA column was reproducibly achieved with high recovery. The figure plots the percentage of the total $U$ recovered that is present in each $1 \mathrm{~mL}$ elution fraction. Thirty-one total fractions were collected and analyzed to ensure all the $U$ had eluted. As seen in the figure, the elution profile is narrow, with all the $U$ washing off the column in a $4 \mathrm{~mL}$ volume.

Additionally, the total $U$ recovery for both Run 1 and Run 2 was calculated from the mass spectrometry data and was better than $99 \%$, with high reproducibility between the replicate analyses. The reduction in the elution volume versus the manual chemistry $(4 \mathrm{~mL}$ vs. $5.5 \mathrm{~mL})$ represents a time savings that is realized in the lengthy dry down step that follows the separation. 


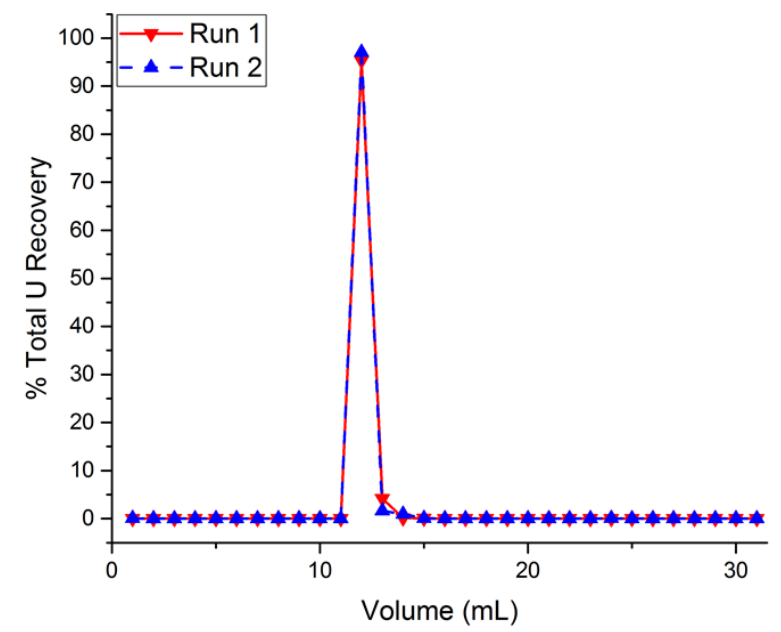

Figure 3. Uranium UTEVA column calibration runs.

Figure 4 shows that the calibration of Pu elution on the TEVA column was reproducibly achieved with high recovery. The plot is the percentage of total $\mathrm{Pu}$ recovered present in each $1 \mathrm{~mL}$ elution fraction. Forty-one total fractions were collected and analyzed to ensure all $\mathrm{Pu}$ had eluted. The elution profile is wider than that for $\mathrm{U}$ but is still reasonably narrow at $8 \mathrm{~mL}$ of acid volume. The total Pu recovery calculated from the mass spectrometry data for Run 1 was $85 \%$ and Run 2 was $58 \%$, both in the range expected from this separation technique. The reduction in the elution volume versus the manual chemistry $(8 \mathrm{~mL}$ vs. $12 \mathrm{~mL})$ represents a time savings that would be realized in the lengthy dry down step that follows the separation.

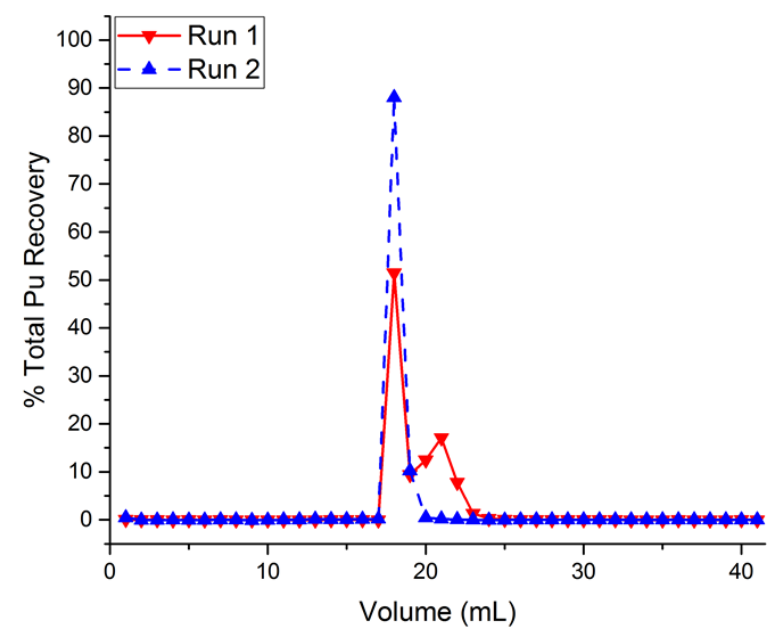

Figure 4. Plutonium TEVA column calibration runs.

Full system calibration for the separation of a mixed U/Pu sample utilizing both columns was achieved under automated control. A high degree of separation between the elution of $U$ (red downward triangles) and $\mathrm{Pu}$ (blue upward triangles) fractions is shown in Figure 5. The total recovery calculated from the mass spectrometry data was $101 \%$ for $\mathrm{U}$, while Pu was $57 \%$. Notably, there is almost $20 \mathrm{~mL}$ of wash volume separating the $\mathrm{U}$ and $\mathrm{Pu}$ elutions, with essentially no $\mathrm{U}$ present in the $\mathrm{Pu}$ fraction, and vice versa. The characterization of these elution profiles with the prepFAST-MC2 running under automated control was critical to establishing the method parameters in the ESI software. Specifically, the wash volumes for the reagents and especially the volumes of the collected sample fractions were optimized using this data. 


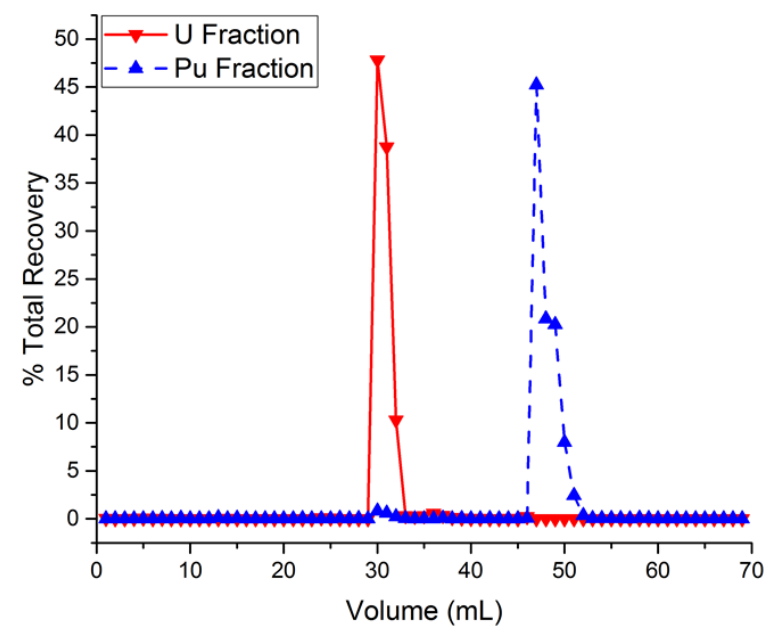

Figure 5. Combined UTEVA (red) and TEVA (blue) column calibration runs for U/Pu separations.

\subsection{COLUMN PACKING AND UNPACKING REPRODUCIBILITY}

Initial studies yielded large deviations in resin mass loadings $(0.475 \pm 0.088 \mathrm{~g}$ and $0.513 \pm 0.075 \mathrm{~g}$ for $\mathrm{C} 1$ and $\mathrm{C} 2$, respectively). Several factors contributed to this, and they were sequentially addressed. Initially, inconsistent pressure during column unpacking led to ineffective unpacking of column $\mathrm{C} 1$. While a T-joint gas line was initially used to unpack both columns simultaneously, as shown in Figure 2, the higher packing efficiency of $\mathrm{C} 1$ led to pressure buildup within the gas line. This caused the pressure to divert to $\mathrm{C} 2$, resulting in residual resin being left in $\mathrm{C} 1$. The first attempt to resolve this uneven pressure was to split the gas line into individual lines. While this initially held promise, it was observed over time that the relatively large diameter of the gas line still allowed pressure buildup within the line. As a result, a smaller internal diameter gas line was used.

Another problem that was addressed was frit blow-outs in the $\mathrm{C} 1$ column during unpacking. As the resin was unpacked with compressed gas, the frit would often break or become unseated at the base of the column. This was originally attributed to the higher pressure after splitting the gas lines; however, a deformity within the column cap was observed and fixed. Additionally, extra care was taken when seating the frit on the column. Combined, these efforts succeeded in eliminating frit blow-outs. Despite these modifications, however, large deviations in the amount of packed resin mass were still observed for $\mathrm{C} 1$ and $\mathrm{C} 2(0.499 \pm 0.043 \mathrm{~g}$ and $0.537 \pm 0.045 \mathrm{~g}$, respectively $)$.

It was observed over a 24 hour period that various amounts of resin would settle inconsistently within the resin lines prior to entering the column. Over this time frame, the resin within the bottles maintained relative homogeneity. Originally, it was hypothesized that priming the resin lines before packing would result in more consistency with the pack. This was not the case, as the priming step required enough volume that resin material entered the columns prior to packing. Attempts to flush the columns were made but proved ineffective at consistently removing all primed resin material from the columns.

Conversely, purging the resin lines back to the resin bottles without refilling the resin lines with liquid caused a vacuum effect, leading to inconsistent packing. As a result, the resin lines were purged with $\mathrm{N}_{2}$ gas and then $5 \% \mathrm{HNO}_{3}$ was back flowed through the columns and resin lines. An air gap was left in the lines to prevent potential resin contamination without creating a vacuum effect. While visually this resulted in more even packing, data showed similar deviations as previously observed $(0.566 \pm 0.053 \mathrm{~g}$ and $0.574 \pm 0.063 \mathrm{~g}$ for $\mathrm{C} 1$ and $\mathrm{C} 2$, respectively); additionally, later runs showed a general increase in amount of resin packed, as seen in Figure 6 and Figure 7. 


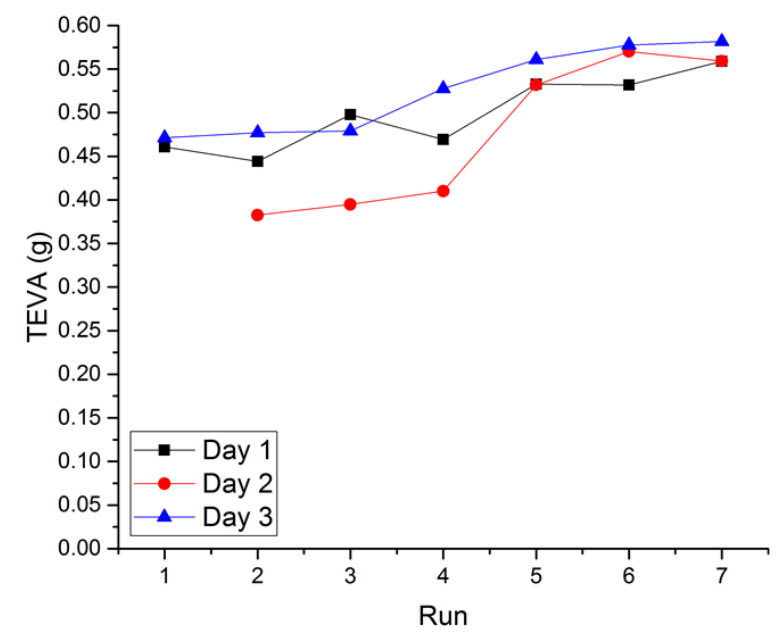

Figure 6. Packing of TEVA (C1) column over 3 days using $500 \mathrm{~mL}$ bottles.

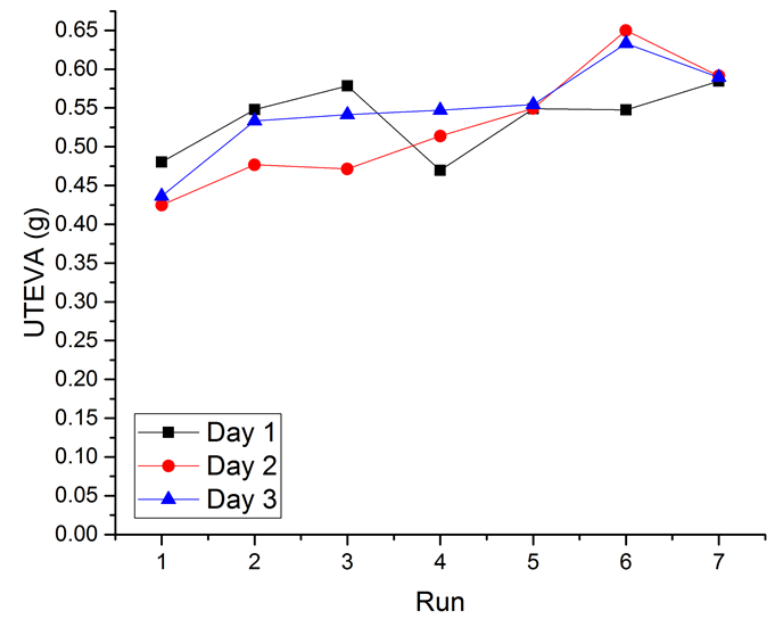

Figure 7. Packing of UTEVA (C2) column over 3 days using $500 \mathrm{~mL}$ bottles.

It was hypothesized that the generally increasing trend observed in the packing of $\mathrm{C} 1$ and $\mathrm{C} 2$ over seven runs could be due to the size of the resin bottle. The initial $500 \mathrm{~mL}$ bottle was approximately $10 \%$ filled with resin for the first runs. The wide surface area of the bottle may allow the resin to settle despite stirring with a $1 \mathrm{in}$. octagonal stir bar. This would affect the homogeneity of the slurry, resulting in more $3 \mathrm{M} \mathrm{HNO}_{3}$ and less resin being pulled into the lines during the initial runs. This would serve to further concentrate the resin within the bottle, which would lead to later runs using an even more concentrated slurry, explaining the increased resin packing weight as a function of time shown in Figure 6 and Figure 7.

To remedy this, $125 \mathrm{~mL}$ Teflon bottles were used with $3 / 4$ in. egg-shaped stir bars. The smaller volume and diameter of the bottle allowed the stir bar to more effectively mix the slurry, leading to more consistent packing that did not increase over time, as shown in Figure 8 and Figure 9. All these fixes combined to decrease the observed daily $(0.556 \pm 0.030 \mathrm{~g}$ and $0.601 \pm 0.019 \mathrm{~g}$ for $\mathrm{C} 1$ and $\mathrm{C} 2$, respectively $)$ and three day $(0.538 \pm 0.037 \mathrm{~g}$ and $0.555 \pm 0.049 \mathrm{~g}$ for $\mathrm{C} 1$ and $\mathrm{C} 2$, respectively) packing deviations to approximately $5 \%$. This variability is similar to values quoted by Eichrom for its prepacked columns. 


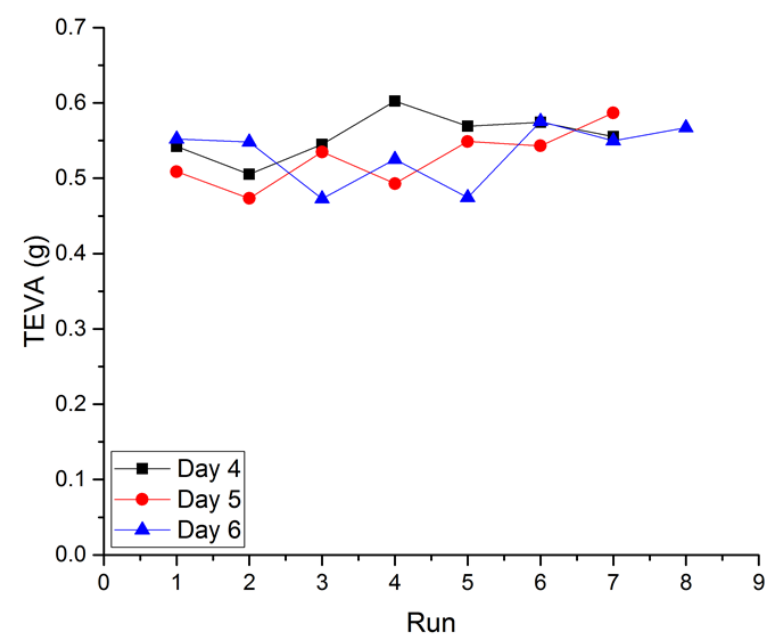

Figure 8. Packing of TEVA (C1) column over 3 days using $125 \mathrm{~mL}$ bottles.

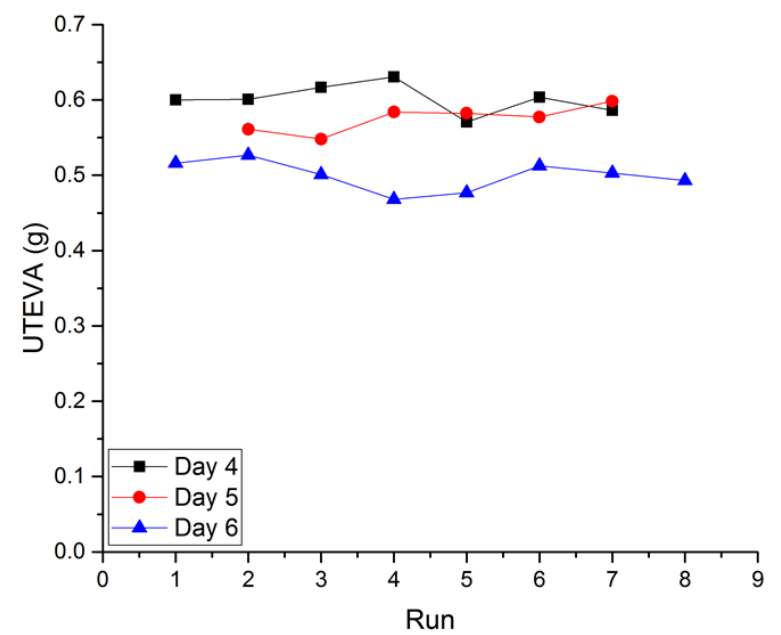

Figure 9. Packing of UTEVA (C2) column over 3 days using $125 \mathrm{~mL}$ bottles.

\subsubsection{SEM Imaging}

The same column frits were used over the course of the packing/unpacking experiments as no visual decrease in packing efficiency was observed over 3 days. An initial suggestion from ESI personnel was that each frit could withstand about 30 pack/unpack cycles, and the observation agreed with this idea. However, to verify that flow through the frits was unimpeded, SEM images of a new frit (Figure 10) and the used frits were taken for comparison (Figure 11 and Figure 12). SEM images confirmed the lack of residual resin built up within the frit. 




Figure 10. Control frit that was not exposed to resin or chemistry.

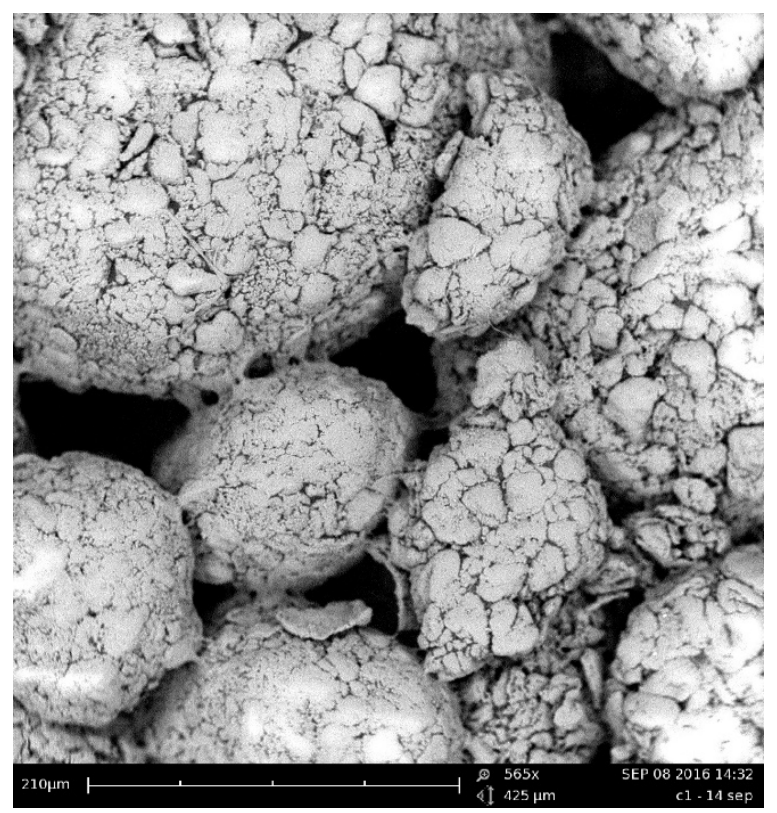

Figure 11. Frit from $\mathrm{C} 1$ column after 30 pack/unpack trials; no chemistry was performed. 


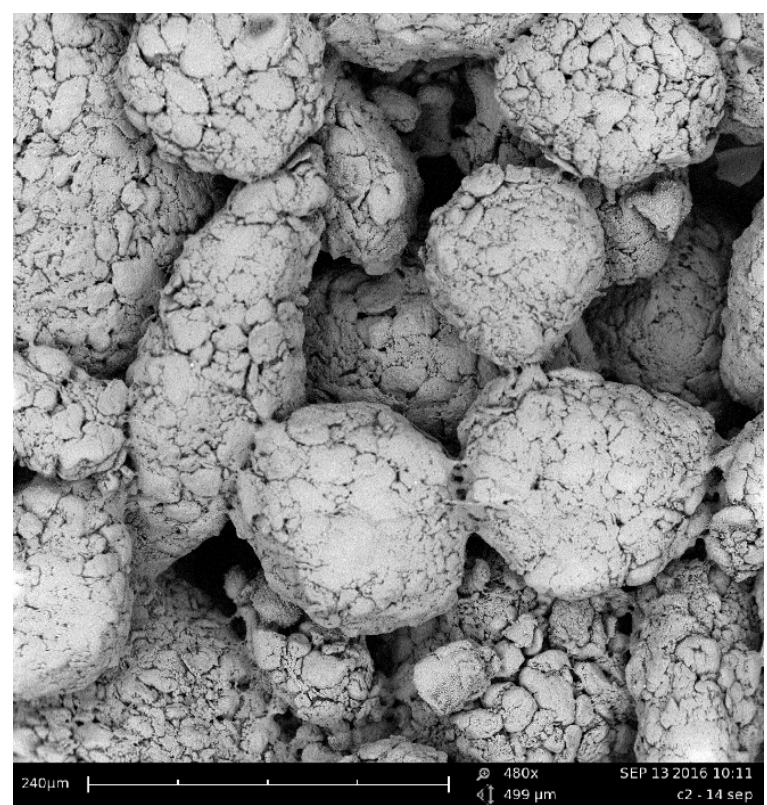

Figure 12. Frit from C2 column after 30 pack/unpack trials; no chemistry was performed.

Separation experiments on mixed U/Pu samples, using the full separation procedure, were started with the intention of using frits for a similar amount of time. At the end of the first day, seven initial separations had been conducted and no decrease in unpacking efficiency was observed. However, at the end of the second day (14 total separations), a significant amount of resin material remained within column $\mathrm{C} 1$. The frits were removed, and SEM images were captured of the frits from C1 (Figure 13) and C2 (Figure 14). They showed significant residual resin when compared to the new frit and the frits used for the pack/unpack tests. Additionally, C1 showed approximately $75 \%$ blockage of the frit, which would contribute to the severe decrease in the unpacking efficiency that was observed at the end of the second day. Because of these results, the frits were replaced every day when new resin material was added to the automated system. After conducting up to nine separations, no decrease in the unpacking efficiency of either column was observed. 


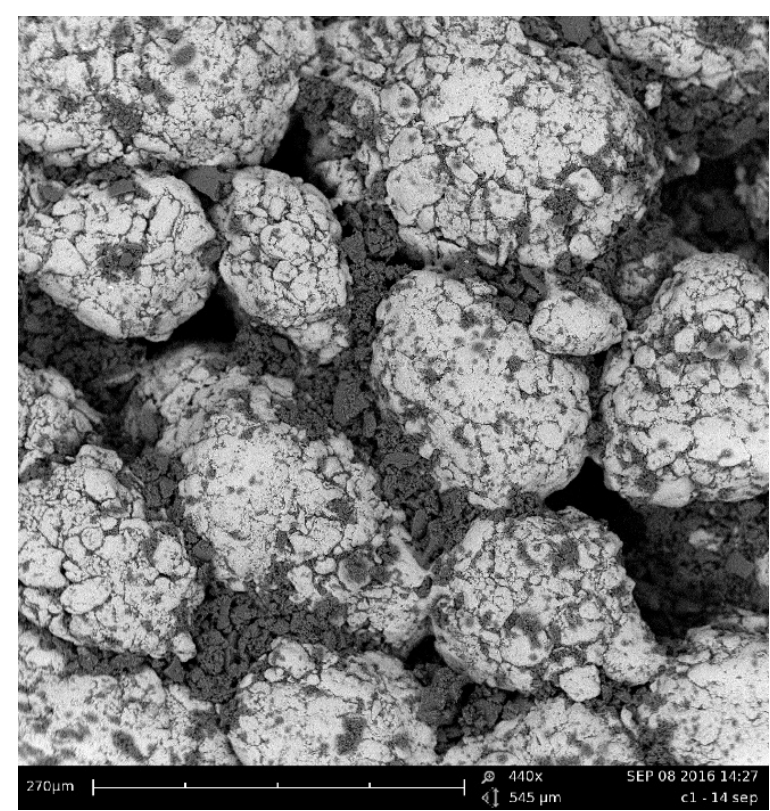

Figure 13. Frit from $\mathrm{C} 1$ column after 14 separations ( $75 \%$ blockage).

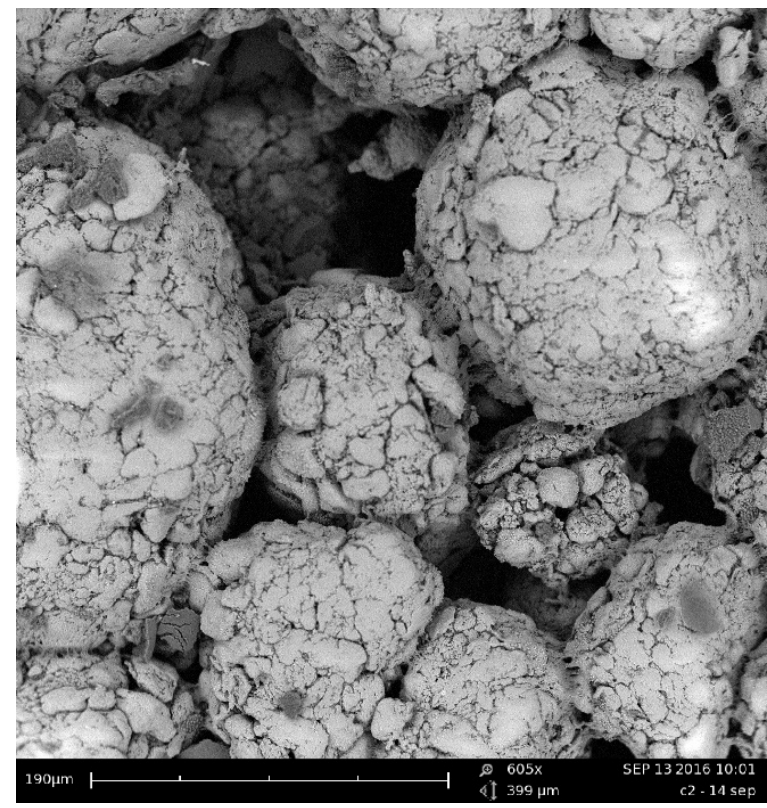

Figure 14. Frit from $\mathrm{C} 2$ column after 14 separations ( $<5 \%$ blockage).

\subsection{CHARACTERIZATION OF SYSTEM PROCESS BLANKS}

Process blanks are samples with no intentionally added $\mathrm{U}$ or Pu but that contain all the reagents used and are taken through all steps of the analytical procedure. For the purposes of these studies, the process blank demonstrates the amount of U/Pu that is inherent to the "process" or the ESI system. It was expected that very little $\mathrm{Pu}$ would be present due to the lack of naturally occurring Pu. However, $\mathrm{U}$ is ubiquitous throughout the environment and will generally be observed at some background level even in process blanks coming from clean rooms. Uranium can be inherently present in materials (e.g., plastics, Teflon, glass, etc.) that contact the samples and in the reagents used, and there can even be a contribution from laboratory air. While steps are taken to reduce the amount of natural $U$ present (i.e., acid leaching new 
containers, use of ultra-pure reagents), some $\mathrm{U}$ background remains. The amount of $\mathrm{U} / \mathrm{Pu}$ in the process blanks is typically measured by the addition of internal isotopic spike standards commonly referred to as isotope dilution mass spectroscopy (IDMS). With a well-characterized IDMS tracer, the amount of U and $\mathrm{Pu}$ added to a blank sample by the system can be accurately determined. For these experiments (as well as the CRMs separations in the next section), the prepFAST-MC2 was moved from the clean room into a different chemical prep laboratory that is not a certified clean room. All chemicals, reagents, samples, and spikes were still prepared in the class 100 clean room and then brought to the other laboratory. Resin was prepared in the lab with the prepFAST.

In order to analyze the amount of $\mathrm{U} / \mathrm{Pu}$ contributed to samples from the prepFAST-MC2, characterization of process blanks was conducted with $3 \mathrm{M} \mathrm{HNO}_{3}$ spiked with CRM IRMM-57 $\left({ }^{233} \mathrm{U}\right)$ and RAL-22 $\left({ }^{244} \mathrm{Pu}\right)$. As described in Section 2.2.3, $\mathrm{FeSO}_{4}$ and $\mathrm{NaNO}_{2}$ were added daily to new spiked blank solutions to adjust the $\mathrm{Pu}$ to the +4 oxidation state, which is required for adsorption onto TEVA resin. Nine spiked blank samples were run consecutively each day on the system in unattended overnight operation. This experiment was repeated over 3 days for a total of 27 blank spiked samples. After the samples were dried down and reconstituted in $2 \% \mathrm{HNO}_{3}$, the samples were measured by MCICPMS. Notably, no samples showed co-elution of the two analytes ( $\mathrm{U}$ in the $\mathrm{Pu}$ fraction or $\mathrm{Pu}$ in the $\mathrm{U}$ fraction).

Examination of the measured $U$ blank concentrations yielded an average $\pm 2 \sigma$ process blank value of $0.01503 \pm 0.00042 \mathrm{ng}$. Figure 15 shows the replicate measurements of the automated process blanks (blue squares) and plots the average ORNL value of the manual clean room process blank for 2015-2016. One sample, where the spike recovery was extremely low $(<1 \%)$, was omitted. As shown in the figure, the prepFAST-MC2 average blank is approximately half the value for the ORNL NWAL manual chemistry, $\sim 15 \mathrm{pg}$ versus $\sim 30 \mathrm{pg}$. Several factors may contribute to the lower blank levels observed, including less handling of the samples during separation, the completely closed sample lines, and smaller elution volumes used for this method.

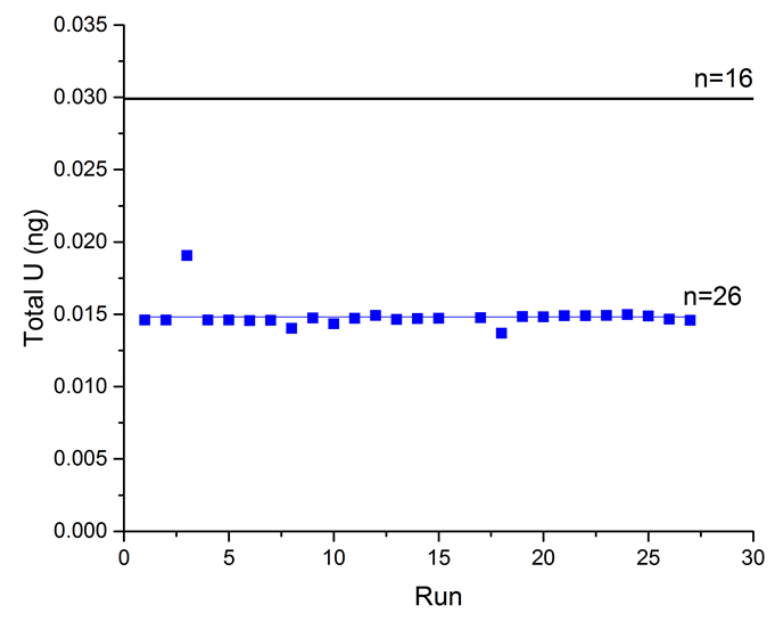

Figure 15. Average and total $U$ in spiked blank samples after spike stripping with $2 \sigma$ error bars compared to the average value from the ORNL NWAL manual chemistry process blanks for 2015-2016 (black).

Figure 16 plots the replicate analyses of the of Pu process blanks, which yielded an average $\pm 2 \sigma$ of $0.00065 \pm 0.00266 \mathrm{pg}$, and the average ORNL value of the manual clean room process blank for 20152016 of $\sim 0.003$ pg. Four samples showed obvious contamination and were omitted from this analysis. All four of these samples were analyzed on the second day, and the contamination in all samples contained similar ${ }^{240} \mathrm{Pu} /{ }^{239} \mathrm{Pu}$ ratios, indicating a common source. The most likely explanation stems from the reuse of sample vials from another application. However, on average the Pu process blanks from the automated operation, as shown by the 23 replicate analyses plotted in Figure 16, were about one-tenth that of the 
ORNL NWAL manual chemistry process blanks from 2015-2016. Similar factors as mentioned for the U blanks could explain the lower Pu blanks as well, especially including less handling of the samples during separation and smaller elution volumes.

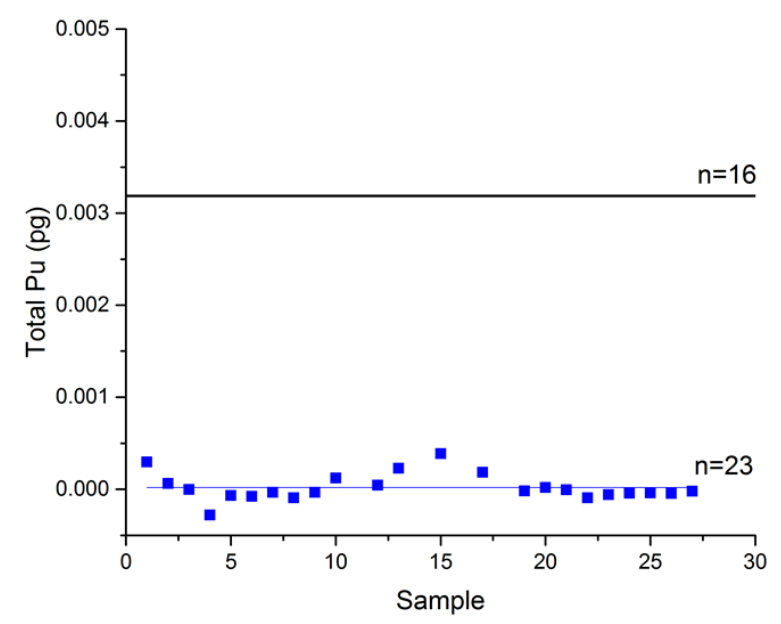

Figure 16. Average and total $P u$ in spiked blank samples after spike stripping with $2 \sigma$ error bars compared to the average value from the ORNL NWAL manual chemistry process blanks for 2015-2016 (black).

An initial concern with unattended overnight operation of the prepFAST-MC2 was the amount of time that elapsed between the addition of redox stabilizers $\left(\mathrm{FeSO}_{4}\right.$ and $\left.\mathrm{NaNO}_{2}\right)$ and the separation of the sample. Figure 17 and Figure 18 plot the measured counts of the ${ }^{233} \mathrm{U}$ and ${ }^{244} \mathrm{Pu}$ spikes across the nine replicate blanks separated in 1 day. If a breakdown of the redox stabilizers was occurring during this time frame, the expected trend would be for a decrease in counts of the spike, indicating a decrease in the percent recovery of the chemistry process. However, as Figure 17 and Figure 18 show, no clear decreasing trend in the measured counts over the course of a day was observed. This demonstrates that preparing all samples, with the redox reagents, together daily at the beginning of a separations sequence is adequate for overnight operation.

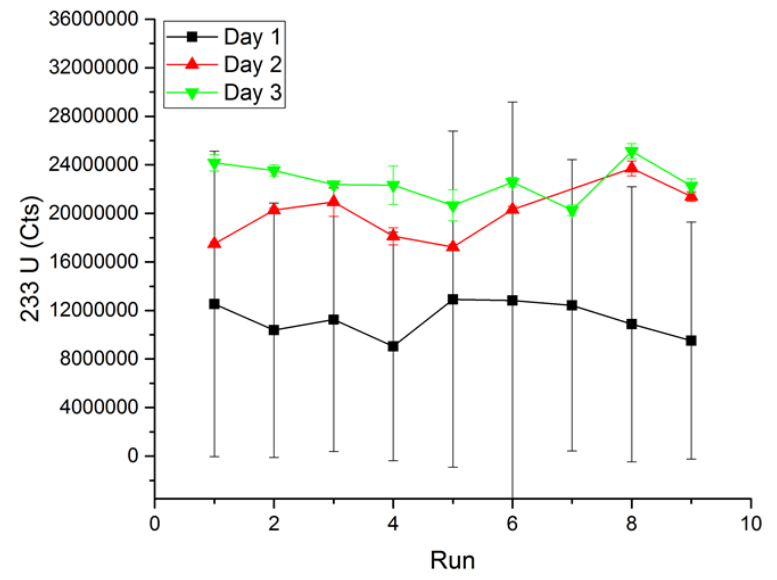

Figure 17. Counts of $U$ in blanks spiked with IRMM-57 $\left({ }^{233} \mathbf{U}\right)$. 


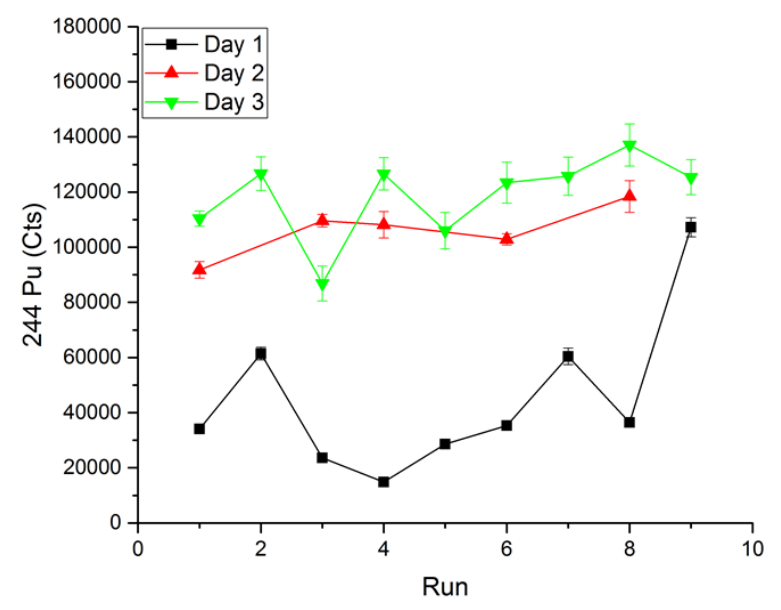

Figure 18. Counts of Pu in blanks spiked with RAL-22 $\left({ }^{244} \mathrm{Pu}\right)$.

As mentioned above, the operation of the prepFAST-MC2 for these experiments occurred outside a clean room. The samples and reagents, however, were still prepared in the clean room. Still, to some degree at least, this represents a worst case scenario for cleanliness. The fact that the system maintained blank levels on the order of those coming out of the manual chemistry conducted in clean room is encouraging for the potential use of this equipment in laboratories without access to an expensive clean room infrastructure. The low blanks achieved without filtered air are attributed to both the entirely sealed sample path and the reduced reagent volumes required for the chemistry. ESI has also committed to the installation of an ultra-low penetration air (ULPA) filter on the sample enclosure on any future models. This will ensure that everything on the sample tray, including both the initial samples and the dispensed, purified aliquots, is only exposed to filtered air. The expectation is that the system can operate as a miniature, portable clean room, and the initial results from the analysis of the blank levels strongly support this conclusion.

\subsection{ANALYSIS OF SEPARATED CERTIFIED REFERENCE MATERIALS}

Initial examination of the column calibration only studied the total amount of $\mathrm{U} / \mathrm{Pu}$ recovered from the system either individually (Figure 3 and Figure 4) or combined (Figure 5). To further investigate the separation of U/Pu utilizing the ESI prepFAST-MC2, samples containing both a U (IRMM-183, 30 ng total) and a Pu (NBL-137, 15 pg total) CRM were separated on the automated system in conjunction with unspiked blank samples. Preparation of the mixed CRM samples and unspiked blank samples were done identically, and the automated system was set up to separate blank, sample, blank, sample, blank, sample, blank overnight. Ultimately, 10 replicate samples and blanks were collected over a 4 day period. The experiment was repeated over several days with different operators performing sample preparation and system setup each day.

The results of the blanks are plotted in Figure 19. Analysis of the blank samples yielded an average amount of total $\mathrm{U}$ of $0.0222 \pm 0.0092 \mathrm{ng}$ (Figure 19 right) that was slightly higher than, but not significantly different from, $\mathrm{U}$ process blanks discussed above. Additionally, isotope ratios for the $\mathrm{U}$ blanks were equivalent to natural $U$ despite being co-processed with samples that contained a depleted $U$ CRM. Plutonium blanks also achieved background levels of $0.0005 \pm 0.0012 \mathrm{pg}$ (Figure 19 left) that were not statistically higher than process blanks. 

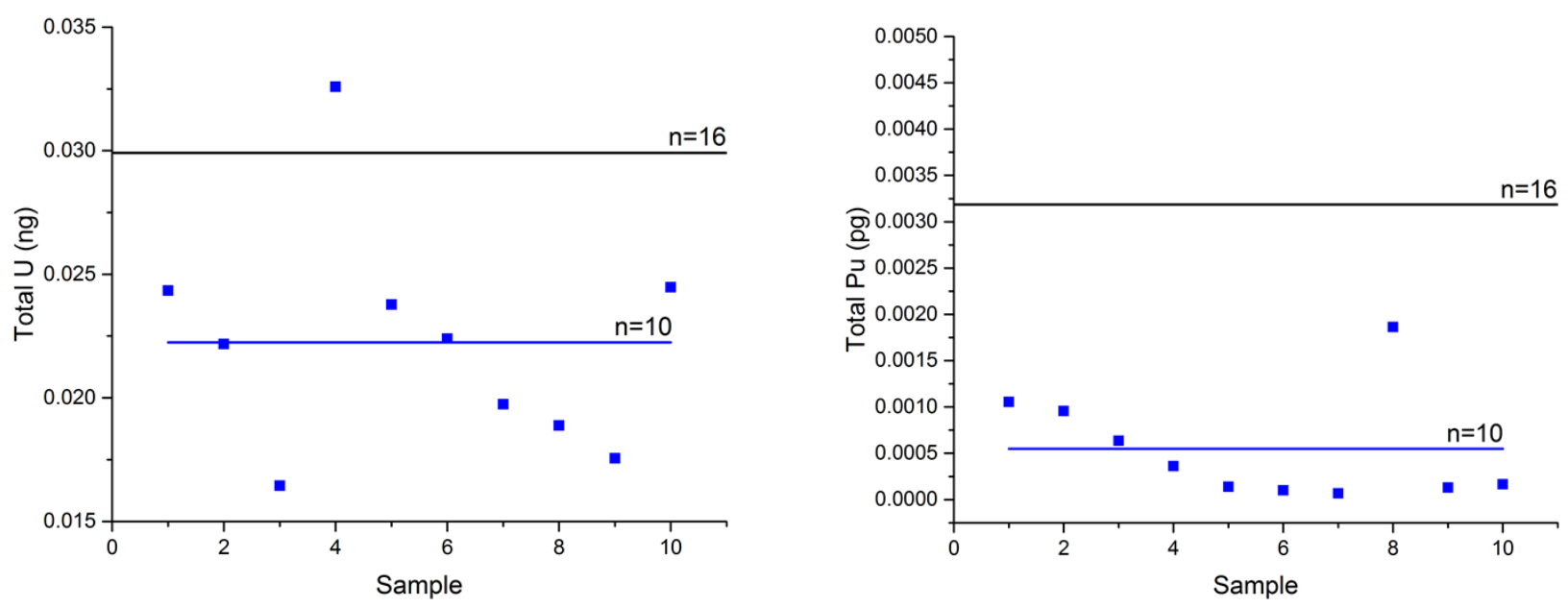

Figure 19. Average and total amount of $U$ (left) and Pu (right) in unspiked blank samples (blue) run intermittently with mixed CRM samples compared to the average ORNL NWAL manual chemistry process blanks for 2015-2016 (black).

All major and minor isotope ratios were measured by MCICPMS in conjunction with mass bias calibration standards, several additional acid blanks, and CRM IRMM-183 or NBL-137 control standards that had not been processed through the prepFAST-MC2. Final isotope ratios for $\mathrm{U}$ and $\mathrm{Pu}$ are given in Table 5, and selected data is plotted in Figure 20 and Figure 21. Uranium data (Figure 20) is plotted with the average value (black line) and $2 \sigma$ (green area) and $3 \sigma$ (magenta area) uncertainties of the replicate analyses of the corresponding control standards. Plutonium data (Figure 21) is similarly plotted with the certified value (black line) and $2 \sigma$ (green area) and $3 \sigma$ (magenta area) uncertainties from the CRM certificate. Data reduction yielded a measured/certified (M/C) value for the major ${ }^{235} \mathrm{U} /{ }^{238} \mathrm{U}$ isotope ratio of 1.0012 , a less than $0.1 \%$ difference, and within the uncertainty expected for this type of analysis. Samples were also compared to the corresponding control standards and show no significant difference, as displayed in Figure 20 (left). The measured ${ }^{236} \mathrm{U} / 238 \mathrm{U}$ isotope ratio for each sample and the controls are also plotted in Figure 20. Both values (sample and controls) were lower than the certified value due to the small number of raw ${ }^{236} \mathrm{U}$ counts collected during measurement. While a $4 \%$ difference was observed in the $\mathrm{M} / \mathrm{C}$ value, this difference is within the IAEA data quality objective standards. Likewise, ${ }^{234} \mathrm{U}$ is not reported here because of low overall counts. Data reduction for the Pu samples yielded $\mathrm{M} / \mathrm{C}$ values very close to the certified values for ${ }^{240} \mathrm{Pu} /{ }^{239} \mathrm{Pu}$ and ${ }^{242} \mathrm{Pu} /{ }^{239} \mathrm{Pu}$ with less than $0.1 \%$ difference (Table 5) and show no statistical difference between the measured and certified values. All Pu samples were within $2 \sigma$ of the certificate values, as shown in Figure 21. The average value for the minor ${ }^{241} \mathrm{Pu} /{ }^{239} \mathrm{Pu}$ ratio was $2.5 \%$ below the certified value, similarly due to low raw ${ }^{242} \mathrm{Pu}$ counts during measurement.

Table 5. Major and minor isotope ratios for $U$ and $P u$ compared to CRM values

\begin{tabular}{|c|c|c|c|}
\hline Ratio & 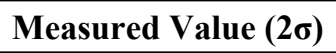 & 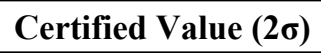 &  \\
\hline $235 / 238 \mathrm{U}$ & $0.0032196(27)$ & $0.0032157(16)$ & $1.0012(20)$ \\
\hline $236 / 238 U$ & $0.0001426(22)$ & $0.000148358(54)$ & $0.961(30)$ \\
\hline 240/239 Pu & $0.24097(73)$ & $0.24077(37)$ & $1.0008(68)$ \\
\hline 241/239 Pu & $0.006627(59)$ & $0.006793(78)$ & $0.975(29)$ \\
\hline 242/239 Pu & $0.01560(13)$ & $0.015611(52)$ & $1.000(18)$ \\
\hline
\end{tabular}



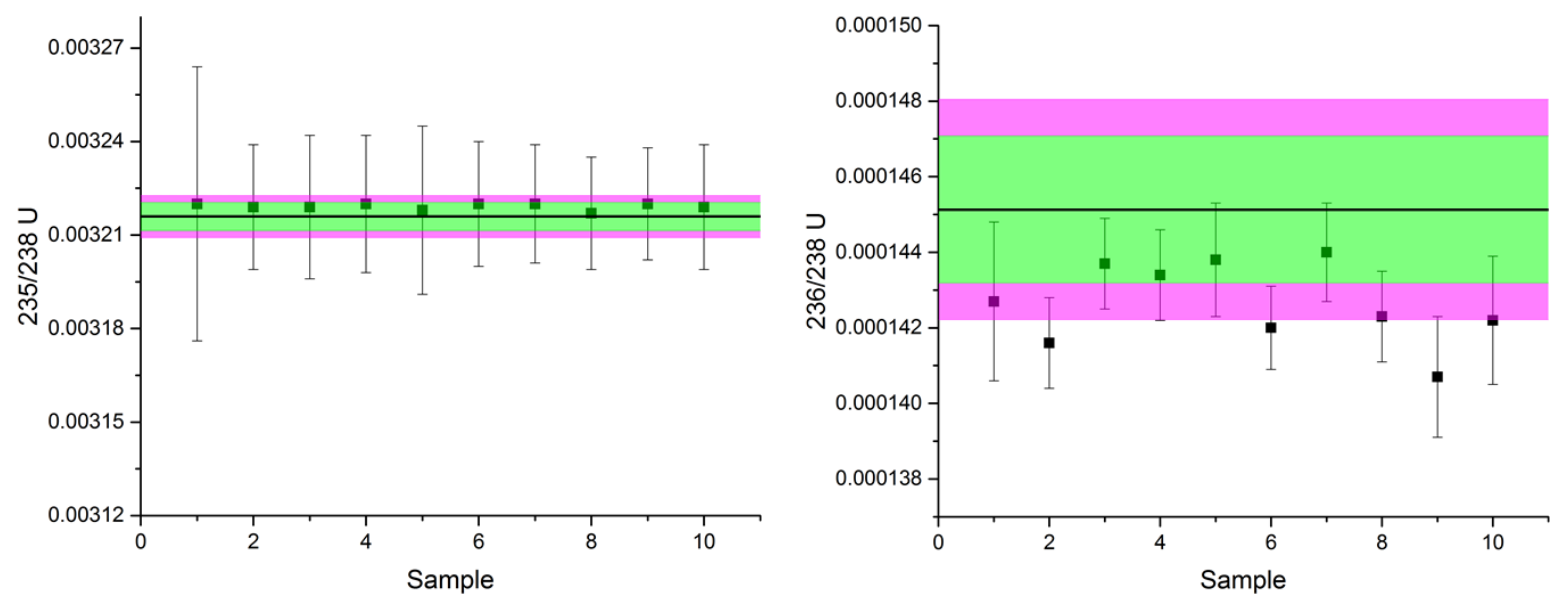

Figure 20. Major $\left({ }^{235} U /{ }^{238} U\right)$ and minor $\left({ }^{236} U /{ }^{238} U\right)$ isotope ratios of $U$ in samples compared to the average value (black line) and $2 \sigma$ (green area) and $3 \sigma$ (magenta area) uncertainties of the replicate analyses of the corresponding control standards control samples of IRMM-183 measured concurrently with samples.
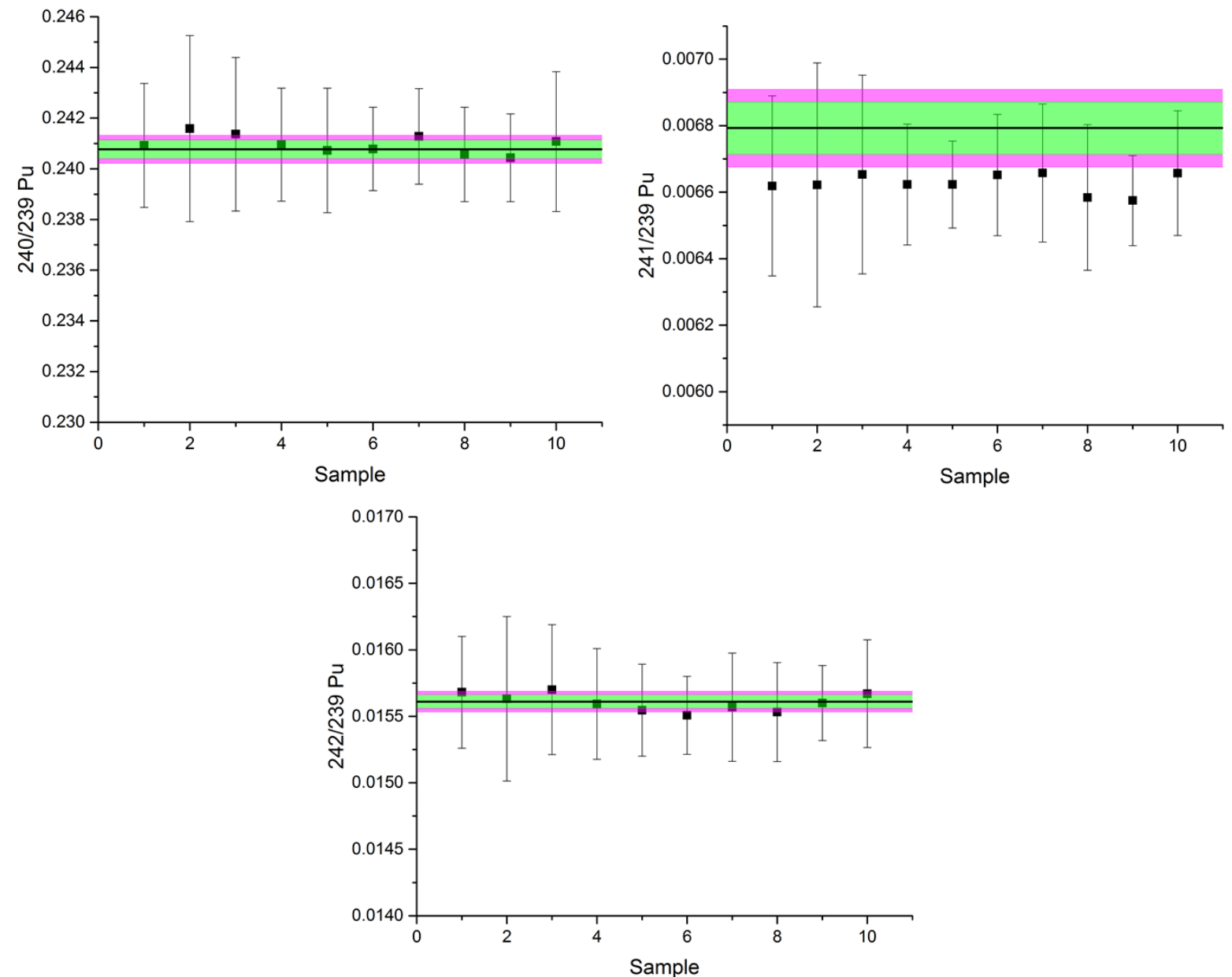

Figure 21. Major $\left({ }^{240} \mathrm{Pu} /{ }^{239} \mathrm{Pu}\right)$ and minor $\left({ }^{241} \mathrm{Pu} /{ }^{239} \mathrm{Pu},{ }^{242} \mathrm{Pu} /{ }^{239} \mathrm{Pu}\right)$ isotope ratios of $\mathrm{Pu}$ in samples compared to the certified value (black line) and $2 \sigma$ (green area) and $3 \sigma$ (magenta area) uncertainties from the CRM certificate isotope ratios for CRM NBL-137. 


\subsection{COMPARISON TO CURRENT NWAL CAPABILITY}

The chemistry of the ESI prepFAST-MC2 was designed to be as close to the ORNL NWAL manual chemistry as possible, with differences outlined in Table 4 . The use of smaller columns allows for smaller elution volumes which can in turn reduce the amount of time spent drying down a sample prior to MCICPMS analysis. Additionally, the smaller elution volumes may lead to lower $U$ and $P u$ content in process blanks. One notable change that has been made is in the elution of the Pu from the TEVA column. Current ORNL NWAL manual chemistry methods utilize $\mathrm{NH}_{4} \mathrm{I}$ as a reducing agent to help remove $\mathrm{Pu}$ from the TEVA column through the reduction of $\mathrm{Pu}^{+4}$ to $\mathrm{Pu}^{+3}$. However, some initial studies revealed high plutonium recoveries without the addition of $\mathrm{NH}_{4} \mathrm{I}$, and Eichrom suggests low acid concentrations can also remove $\mathrm{Pu}$ from TEVA resin without the reduction step. Additionally, $\mathrm{NH}_{4} \mathrm{I}$ is photosensitive, and the prototype prepFAST-MC2 has two LED lights behind the columns that are on continuously in the solvent storage area. The relatively quick decomposition of $\mathrm{NH}_{4} \mathrm{I}$ in aqueous solution and sensitivity to light would necessitate that the solution be made fresh daily. As the experiments described above were conducted at moderate plutonium concentrations $(>2 \mathrm{pg}), \mathrm{NH}_{4} \mathrm{I}$ was not used in these separations. Future studies in FY 17 are planned to further explore the need for a reducing agent during the separations, which may become critical at low Pu concentrations (i.e., $<1 \mathrm{pg}$ ). Additionally, ESI plans to modify the prepFAST-MC2 light source to shut off when panel doors are closed so as not to contribute to the decomposition of the $\mathrm{NH}_{4} \mathrm{I}$ solution.

\section{TIME AND COST SAVINGS}

The automation of the chemical separations step allows for unattended overnight operation of the system. ORNL NWAL manual chemistry requires 8 hours of hands-on personnel time to separate seven samples in tandem, as was documented on a recent set of actual NWAL samples. The prepFAST-MC2 requires less than 30 minutes of hands-on personnel time before automated separations start. The time is spent adding new resin to resin bottles, changing frits, loading collection vials, and loading method(s) in the software. Once these quick activities are complete, an operator can start the system and return when the separations are completed and purified sample aliquots have been dispensed into vials. While the total amount of time spent processing IAEA swipe samples is estimated to be nearly the same, the amount of personnel time required for the ORNL NWAL manual chemistry is significantly more ( $\sim 10$ hours vs less than 1 hour) than that required for the automated system. This time savings is graphically depicted in Figure 22 and documented in Table 6 . The time savings translates to a significant cost savings, as the most expensive part of any single sample analysis is personnel labor costs. 


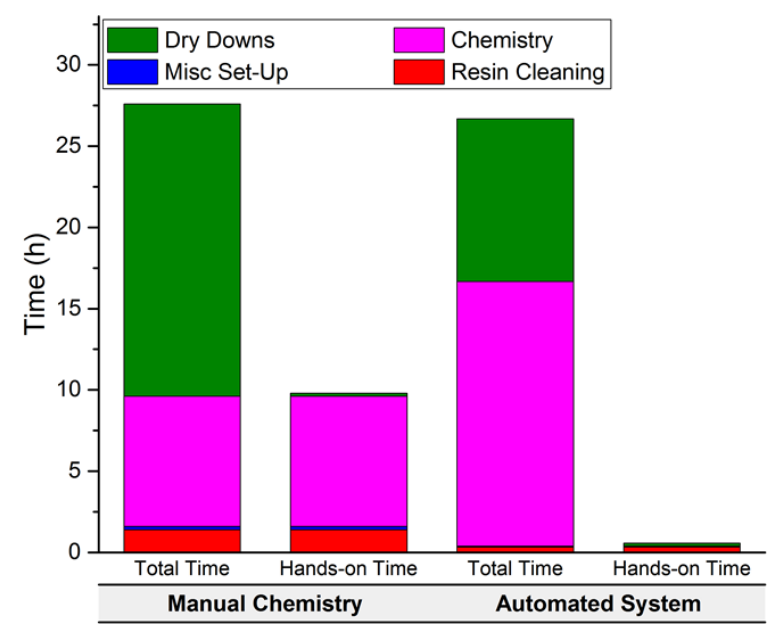

Figure 22. Time comparison chart of ORNL NWAL manual chemistry and ESI prepFAST-MC2 automated system with total time and hands-on time shown.

Table 6. Time comparison of ORNL NWAL manual chemistry and ESI prepFAST-MC2 automated system

\begin{tabular}{ccccc}
\hline \multirow{2}{*}{ Sub-Steps } & \multicolumn{2}{c}{ Manual Chemistry } & \multicolumn{2}{c}{ Automated System } \\
\cline { 2 - 5 } & Total Time (h) & Hands-on Time (h) & Total Time (h) & Hands-on Time (h) \\
\hline Resin Cleaning & 1.4 & 1.4 & 0.33 & 0.33 \\
Misc. Setup & 0.2 & 0.2 & 0.05 & 0.05 \\
Chemistry & 8 & 8 & 16.3 & 0 \\
Dry Downs & 18 & 0.2 & 10 & 0.2 \\
Total & $\mathbf{2 7 . 6}$ & $\mathbf{9 . 8}$ & $\mathbf{2 6 . 6 8}$ & $\mathbf{0 . 5 8}$ \\
\hline
\end{tabular}

Additionally, it would be possible to operate several automated systems simultaneously, thus increasing throughput without adding significant hands-on personnel time. Manual chemistry is limited to processing at most a dozen samples at one time. Both the cost and the relatively small laboratory footprint make operation of multiple systems feasible, which would produce even greater efficiency gains. The use of multiple prepFAST-MC2 systems would also allow segregation of samples by content, as is typically done by NWAL laboratories already. A lab could have a prepFAST-MC2 for hot swipes and another one for cold swipes, minimizing the chance of cross-contamination between samples.

\section{CONCLUSIONS}

ORNL has partnered with ESI to customize its existing prepFAST-MC to automate the separation of U and $\mathrm{Pu}$ from bulk environmental samples to support IAEA NWAL analysis. The resulting system, the prepFAST-MC2, requires 35 minutes of manual preparation time and can operate overnight in an unattended mode. Up to 10 samples and blanks can be separated sequentially before the system is reset with new reagents and samples. However, multiple prepFAST-MC2 stations can be operated to increase sample throughput. Purified $\mathrm{U}$ and Pu aliquots for each sample are then dried down, reconstituted, and available for MCICPMS analysis.

The prepFAST-MC2 is based on the ORNL NWAL chemical procedure, which uses Eichrom UTEVA and TEVA resins to extract $\mathrm{U}$ and $\mathrm{Pu}$, respectively. The automated system packs and unpacks columns with fresh resin for each separation, avoiding potential cross-contamination from the reuse of resin. The packing step for both UTEVA and TEVA resins is critical for consistent separations, and significant effort 
was placed on achieving highly reproducible packing weights. Variations on the amount of packed resin were about $5 \%$, which was as good or better than the variation in the pre-packed columns sold by Eichrom.

The elution profiles of the columns were also carefully characterized. This ensured that the final method developed achieved significant separation between $\mathrm{U}$ and $\mathrm{Pu}$ in the final purified aliquots. It also helped identify the volume of the final aliquots needed to ensure complete recovery of $U$ and $\mathrm{Pu}$. Based on this data, the elution volumes were reduced for both $\mathrm{U}$ (from 5.5 to $4 \mathrm{~mL}$ ) and $\mathrm{Pu}$ (from 12 to $8 \mathrm{~mL}$ ). This reduction in elution volume may lead to cleaner blank levels and will lead to time savings by reducing dry down times.

Finally, the low $\mathrm{U}$ and Pu blank levels initially achieved with the prepFAST-MC2 confirm that it can produce high-quality results without the need for an expensive clean room infrastructure. This is an especially significant advantage for many laboratories, especially internationally, that do not have the resources to support multiple clean room facilities.

The performance of the system was then verified by the separation of mixed U/Pu samples that consisted of isotopic CRMs. They were run interspersed with blanks and analyzed by MCICPMS. The results showed that the purified samples closely matched the expected values from the certificates of the CRMs. This indicates that the samples were not isotopically contaminated by processing and purified aliquots are suitable for high-precision mass spectrometric analysis, both of which are essential for eventual use in NWAL analysis. Additionally, the process blanks run between every sample contained very low levels of $\mathrm{U}(\sim 22 \mathrm{pg})$ and $\mathrm{Pu}(\sim 0.5 \mathrm{fg})$, proving that the system is completely washed out between samples, with no carryover or cross-contamination.

Finally, the time savings of the unattended, automated operation was documented directly versus the ORNL manual chemistry. For seven samples analyzed together, the total time for the automated system was 26.7 hours, versus 27.7 hours for the manual chemistry. However, when actual hands-on labor is considered, the automated chemistry only requires 35 minutes of preparation time, while the manual chemistry requires 9.8 hours of labor. This represents a savings of more than $90 \%$ on labor. Additionally, multiple systems could be implemented in the same laboratory to leverage the gains in the efficiency of labor.

Future studies will include evaluating the quality of actinide separation in samples containing high $U$ content relative to $\mathrm{Pu}$. Also important is the effectiveness of the separation to remove elemental interferences, such at $\mathrm{Hg}, \mathrm{Pb}, \mathrm{W}$, etc., that form polyatomic interferences in the $\mathrm{U}$ and $\mathrm{Pu}$ mass range. The need for a reducing agent such as $\mathrm{NH}_{4} \mathrm{I}$ in the eluent will be assessed to determine whether it is required for consistent and quantitative recovery of Pu over the mass range of femtograms through $50 \mathrm{pg}$. Finally, archived fractions of actual IAEA fractions will be processed by the prepFAST-MC2 system, and results will be compared that those previously acquired by manual ORNL NWAL protocol.

\section{REFERENCES}

1. IAEA, IAEA Safeguards Glossary. International Atomic Energy Agency: Vienna, 2002.

2. Recommendations from the 2010 IAEA Technical Meeting: Bulk Analysis of Environmental Samples for Safeguards. International Atomic Energy Agency: Vienna, 2010.

3. IAEA Department of Safeguards Long-Term R\&D Plan, 2012-2023. International Atomic Energy Agency: Vienna, 2013. 
4. Development and Implementation Support Programme for Nuclear Verification 2016-2017. International Atomic Energy Agency: Vienna, 2016.

5. Field, P. M. prepFAST-MC ${ }^{T M}$ : Automating Sample Purification. Elemental Scientific Inc.: 2014. 